Florida International University FIU Digital Commons

7-14-2009

\title{
The Impact of a Family Home-learning Program on levels of Parental/Caregiver Efficacy
}

Tomasine A. Morrison

Florida International University, tomasinem@earthlink.net

DOI: $10.25148 /$ etd.FI09082404

Follow this and additional works at: https://digitalcommons.fiu.edu/etd

\section{Recommended Citation}

Morrison, Tomasine A., "The Impact of a Family Home-learning Program on levels of Parental/Caregiver Efficacy" (2009). FIU Electronic Theses and Dissertations. 102.

https://digitalcommons.fiu.edu/etd/102 


\section{FLORIDA INTERNATIONAL UNIVERSITY}

Miami, Florida

THE IMPACT OF A FAMILY HOME-LEARNING PROGRAM

ON LEVELS OF PARENTAL/CAREGIVER EFFICACY

A dissertation submitted in partial fulfillment of the

requirements for the degree of

DOCTOR OF EDUCATION

in

EDUCATIONAL ADMINISTRATION AND

SUPERVISION

by

Tomasine A. Morrison

2009 
To: Interim Dean Kingsley Banya

College of Education

This dissertation, written by Tomasine A. Morrison, and entitled The Impact of a Family Home-learning Program on Levels of Parental/Caregiver Efficacy, having been approved in respect to style and intellectual content, is referred to you for judgment.

We have read this dissertation and recommend that it be approved.

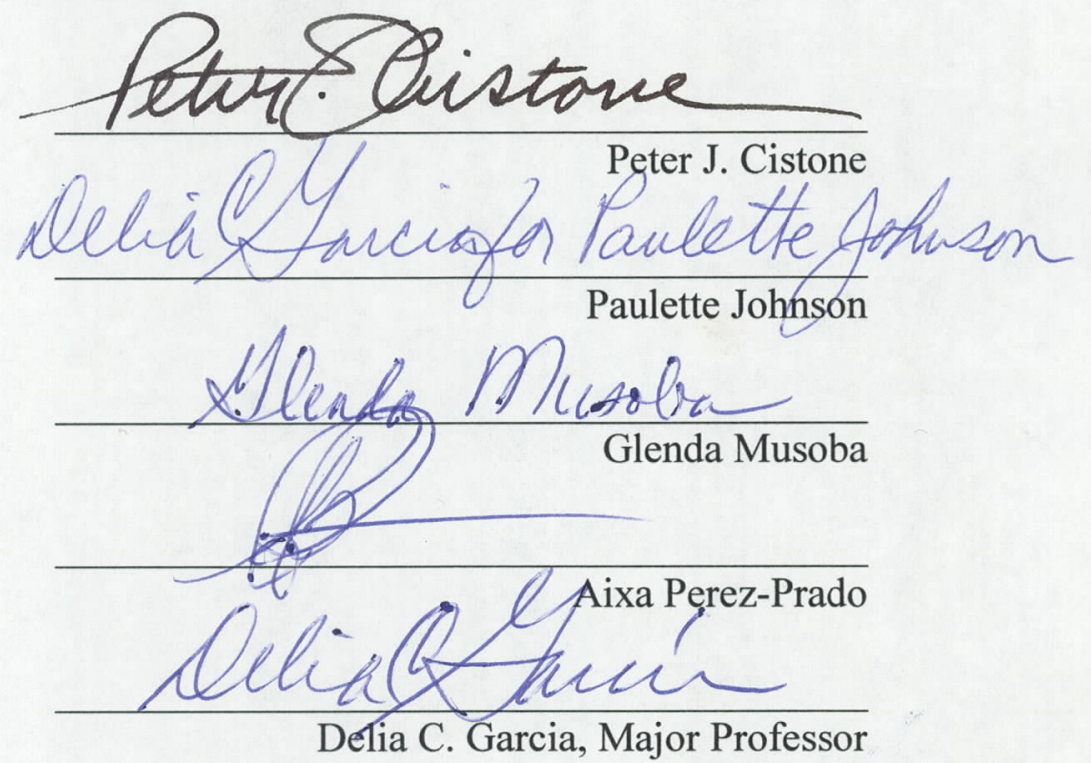

Date of Defense: July 14, 2009

The dissertation of Tomasine A. Morrison is approved.

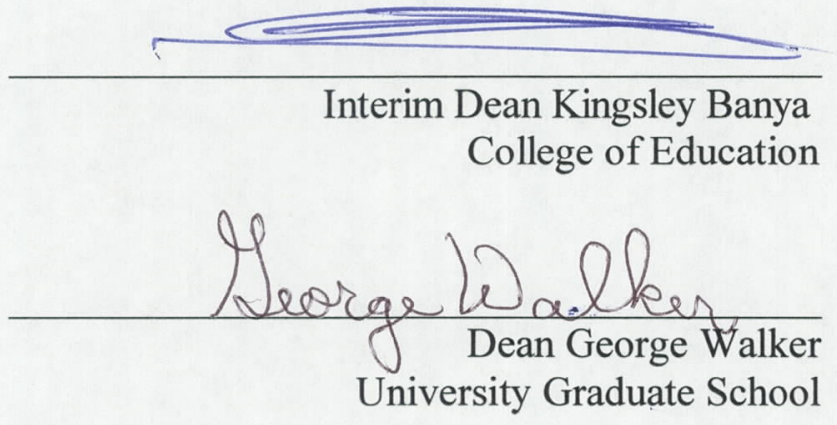

Florida International University, 2009 


\section{DEDICATION}

This work is dedicated to my husband, Kevin, and my children and grandchildren whose love and support has strengthened me throughout my many years of study.

In memory of my father Michael Soper, Sr. who taught me the love of learning. 


\section{ACKNOWLEDGMENTS}

I would like to acknowledge and thank the professors on my committee, Dr. Peter J.

Cistone, Dr. Paulette Johnson, Dr. Glenda Musoba, Dr. Aixa Perez-Prado, and the committee chair, Dr. Delia C. Garcia. I would especially like to thank Dr. Cistone for his mentorship and Dr. Garcia for her dedication and persistence in seeing this research study to its completion. I would also like to thank my family for their endless support and love. 


\section{ABSTRACT OF THE DISSERTATION \\ THE IMPACT OF A FAMILY HOME-LEARNING PROGRAM \\ ON LEVELS OF PARENTAL/CAREGIVER EFFICACY}

by

Tomasine A. Morrison

Florida International University, 2009

Miami, Florida

\section{Professor Delia C. Garcia, Major Professor}

This study sought to determine if participation in a home education learning program would impact the perceived levels of parental self-efficacy of parents/caregivers who participate in the completion of home-learning assignments and increase their levels of home-learning involvement practices. Also, the study examined the relationship between the parental involvement practice of completing interactive home-learning assignments and the reading comprehension achievement of first grade students.

A total of 146 students and their parents/caregivers representing a convenience sample of eight first grade classes participated in the study. Four classes $(n=74)$ were selected as the experimental group and four classes $(n=72)$ served as the control group. . There were 72 girls in the sample and 74 boys and the median age was 6 years 6 months.

The study employed a quasi-experimental research design utilizing eight existing first grade classes. It examined the effects of a home-learning support intervention program on the perceived efficacy levels of the participating parents/caregivers, as measured by the Parent Perceptions of Parent Efficacy Scale (Hoover-Dempsey, Bassler, \& Brissie, 1992) administered on a pre/post basis. The amount and type of parent 
involvement in the completion of home assignments was determined by means of a locally developed instrument, the H.E.L.P. Parent Involvement Home-learning Scale, administered on a pre/post basis. Student achievement in reading comprehension was measured via the reading subtest of the Brigance, CIB-S pre and post.

The elementary students and their parents/caregivers participated in an interactive home-learning intervention program for 12 weeks that required parent/caregiver assistance. Results revealed the experimental group of parents/caregivers had a significant increase in their levels of perceived self-efficacy, $\mathrm{p}<.001$, from the pre to post, and also had significantly increased levels of parental involvement in seven homelearning activities, $\mathrm{p}<.001$, than the control group parents/caregivers. The experimental group students demonstrated significantly higher reading levels than the control group students, $\mathrm{p}<.001$. This study provided evidence that interactive home-learning activities improved the levels of parental self-efficacy and parental involvement in home-learning activities, and improved the reading comprehension of the experimental group in comparison to the control. 


\section{TABLE OF CONTENTS}

CHAPTER

PAGE

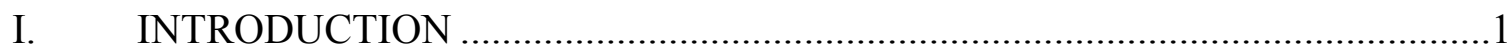

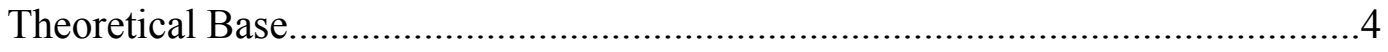

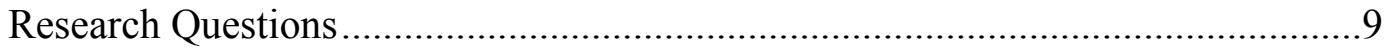

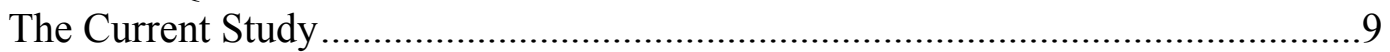

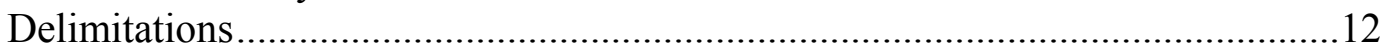

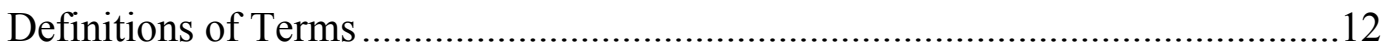

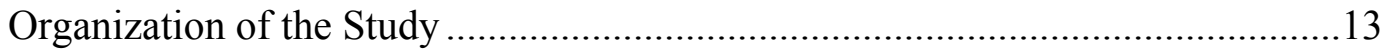

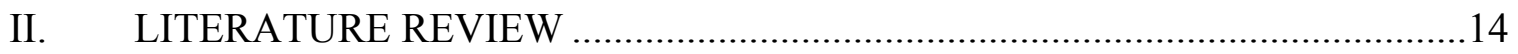

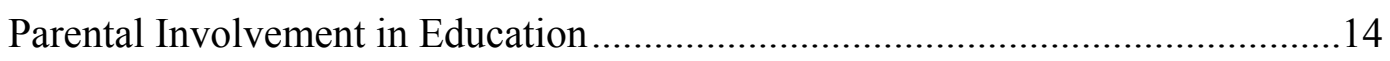

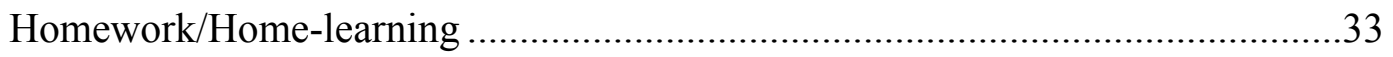

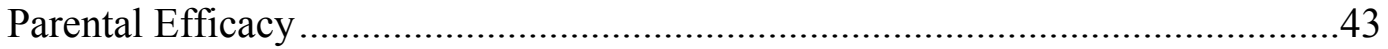

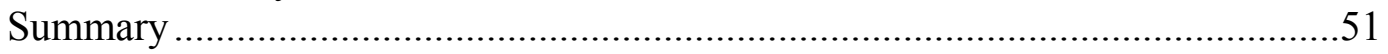

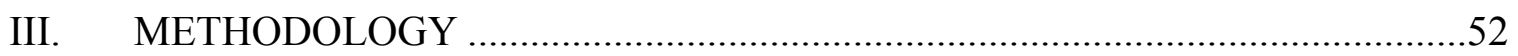

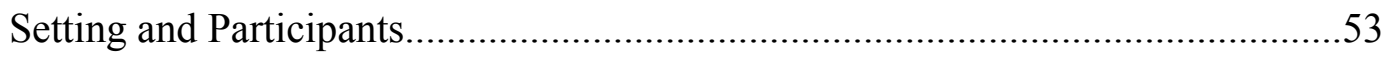

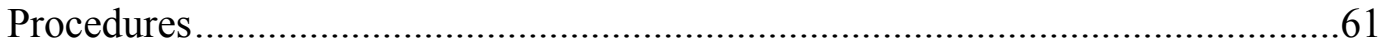

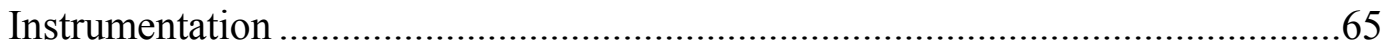

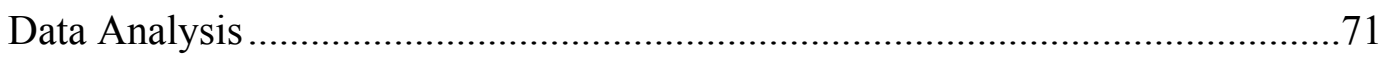

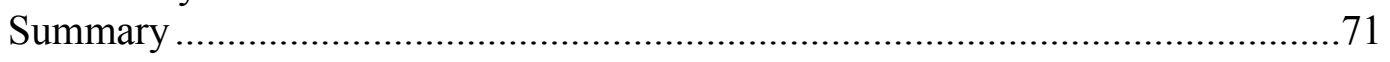

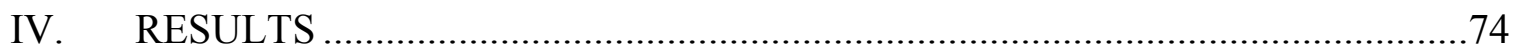

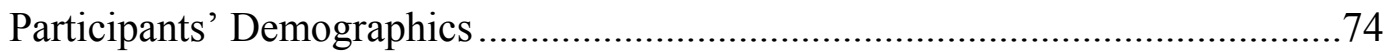

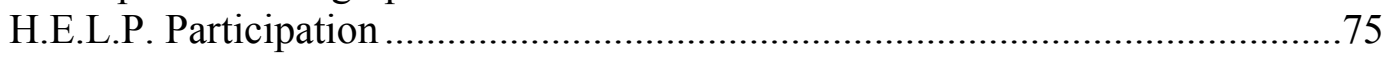

Results for the Research Questions......................................................................77

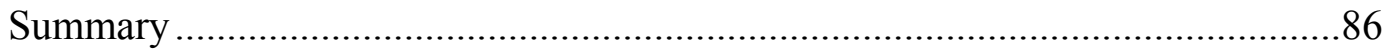

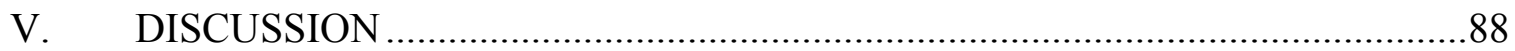

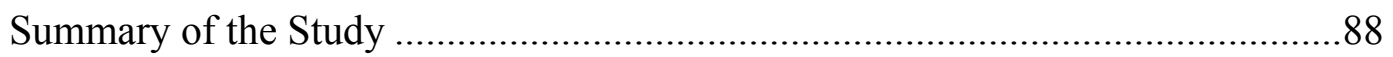

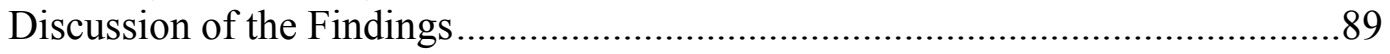

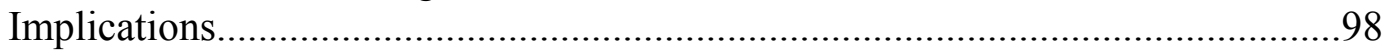

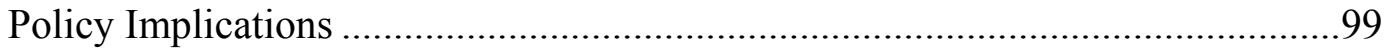

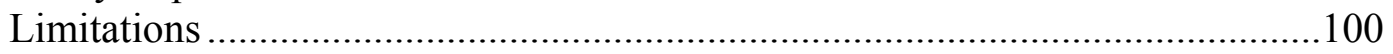

Recommendations for Further Research.........................................................100

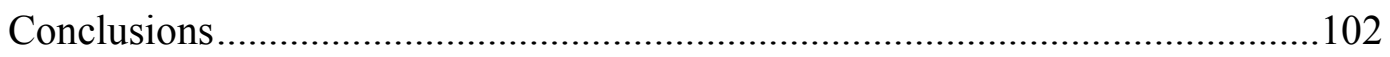

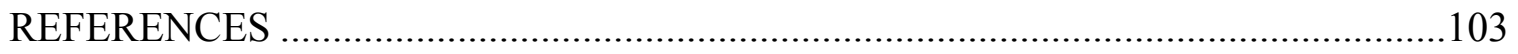

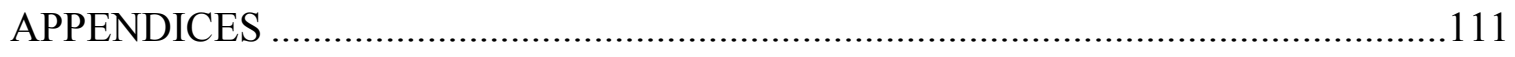

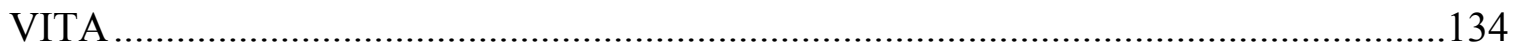




\section{LIST OF TABLES}

TABLE

PAGE

1. Comparison of State, County, School, and Study Populations by Percent of Population

2. Comparison of the Subjects from Project H.E.L.P. by Racial/Ethnic

Category for the Experimental Group and the Control Group .56

3. Comparison of the Subjects from Project H.E.L.P. by Gender for the Experimental Group and the Control Group

4. Teachers' Demographic Information by Group Assignment...............................58

5. Results of the Parent Involvement Practices Survey ......................................60

6. Results of the Field Test Survey Questions ..................................................69

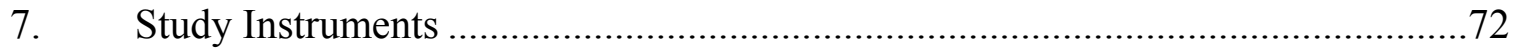

8. Frequencies and Percentages of Demographic Data from the Parent Questionnaires for Experimental Group and the Control Group .........................76

9. Frequencies and Percentages of Packets Completed by Participants in H.E.L.P.

10. Comparison of the Pre and Post Test Means on the Parent Perceptions of

Parent Efficacy Scale by Group....

11. Comparison of the Experimental Group and the Control Group

Mean Increases Pre to Post on the Parent Perceptions

of Parent Efficacy Scale.

12. Comparison of the Experimental Group and Control Group Mean

Differences from Pre to Post on the Parent Perceptions of Parent

Efficacy Scale

13. Pre and Post Test Results for the Experimental Group and

Control Group on H.E.L.P. Parent Involvement in

Home-Learning Scale

14. Comparison of the Pre and Post Test Means on the Brigance Diagnostic

Comprehensive Inventory of Basic Skills Reading Comprehension by Group 
15. Comparison of the Experimental Group and Control Group Mean Increases Pre to Post on the Brigance Diagnostic Comprehensive Inventory of Basic Skills Reading Comprehension 


\section{CHAPTER I}

\section{INTRODUCTION}

One of the biggest problems facing educators and society in America today is the poor reading achievement of students. The U.S. Department of Health and Human Services (2008) reported that $32.84 \%$ of our nation's fourth grade students and $25.96 \%$ of our eighth grade students were below the basic level in reading. Over 42 million American adults cannot read at all, and over 50 million can read at no higher than a fourth or fifth grade level. Twenty percent of all seniors graduating from high school can be classified as being functionally illiterate according to the National Right to Read Foundation (2008). Illiteracy is connected to many of the social problems facing the nation today. In state and federal prisons, $70 \%$ of the prisoners can be classified as illiterate, and among juvenile offenders, $85 \%$ are classified as functionally or marginally illiterate. This situation is further compounded by the fact that approximately $42 \%$ of Americans with the lowest literacy skills live in poverty (National Institute for Literacy, 2008).

In light of these realities, this study targeted parent/caregivers and their children in a rural area of the southeastern United States that is struggling with many of the same problems as the nation. The district has low rates of high school completion (45\%) and a 23\% illiteracy rate (Emory University Strategic Planning, 2004). Schools in this region report poor scores in reading comprehension throughout the elementary grades. By the fifth grade, $21 \%$ of area students are below state standards in reading (Georgia Department of Education, 2007). Additionally, the area is struggling with new demands 
placed on the school system resulting from the growth in population, doubling between 1980 and 2000, and projected to triple by 2010 (Emory University Strategic Planning, 2004). As a result, the area is experiencing an increase in single parent households, English language learners and greater diversity of residents. Districts in the area are struggling to meet the varied demands that new residents place on public schools including over-crowded schools, teacher shortages, and increases in special services to students.

Administrators are continuously seeking new ways to increase reading scores for the students in their schools through new curricular frameworks/approaches and other interventions. Research indicates that one positive approach is to provide more opportunities for parents/caregivers to participate in the educational process of their children (Baker \& Sodon, 1997; Epstein \& Sanders, 2000). Because of the changing demographics, traditional approaches to parent involvement have been unsuccessful. Working and single parents have little time to attend activities and workshops at the school during school hours that would help them learn the skills they need to assist their children with academic tasks.

One traditional approach used to promote greater parental participation is homework, now referred to as home-learning. Home-learning is defined as involvement of families with their children in learning activities at home, including homework and other curricular linked activities (Epstein, 1996). In this type of parent involvement, parents are involved in monitoring and assisting children with the completion of learning activities. Home-learning has been identified as a critical component of parent/caregiver involvement programs and is a mandated part of many school improvement efforts 
(Baker \& Sodon, 1998). The term "parent/caregivers" includes parents, grandparents, step-parents, foster parents, and others who care for the children at home.

Home-learning in the area of reading has been shown to improve student achievement (Fantussio, Davis, \& Ginsburg, 1995; Jordan, Snow, \& Porche, 2000; Zellman \& Waterman, 1998). Parents/caregivers generally receive little training or guidance in the techniques that are required to guide children through the literacy acquisition process. Where parental in-service programs are available, they generally require parental attendance at school workshops during parental work hours, a practice that prohibits many parents from participating. By being unavailable to attend workshops that provide valuable information and skills, parents miss opportunities to develop confidence in their ability to help their child. If parents do not feel competent to assist their students with home-learning, they may be less likely to participate in this important process with their children (Hoover-Dempsey \& Sandler, 1995).

The concept that individuals will undertake tasks they feel confident that they can accomplish, and will avoid tasks they feel they cannot accomplish, was proposed by Bandura (1977) in his research concerning expectations and self-efficacy. Self-efficacy is a person's belief that he or she is capable of exerting a positive influence on an outcome (Bandura, 1986). Parents high in efficacy will be more likely to engage in behaviors leading to a goal and will be more persistent in the face of obstacles than will parents with a lower sense of efficacy (Hoover-Dempsey, Bassler, \& Brissie, 1992). This study was designed to determine if a home-learning program would positively affect parents'/caregivers' self-perceptions of their ability to affect their child's academic outcomes. Also, examined was if parents/caregivers would increase their levels of 
involvement in home-learning by participating in reading activities with their child. Ultimately, the study sought to determine the effects of involving parents/caregivers in the teaching of the reading process, at home, on the reading achievement of students, as measured on standardized tests. Findings from this study could provide valuable models for school administrators interested in increasing parents/caregivers school involvement practices in an effort to impact the reading comprehension achievement of students.

Theoretical Base

Early research in parent involvement began in the 1960s when studies by behavioral scientists found evidence that a child's early environment had a deep effect on the child's development. This research resulted in the creation of government programs such as Head Start and Follow-Through (Berger, 1981). Head Start aimed at promoting the school readiness of children by enhancing their social and cognitive development through the direct provision of educational, health, nutritional, social and other services of enrolled children and their families (U.S. Department of Health and Human Services, 2008). The program engaged parents in their children's learning and helped parents make progress toward their educational, literacy and employment goals. Significant emphasis was placed on the involvement of parents in the administration of local Head Start programs. Project Follow-Through was designed to continue Head Start services to students in their early elementary years (U.S. Department of Health and Human Services).

In the 1970s, new legislation that included parent involvement components began to emerge. Laws including The Family Educational Rights and Privacy Act of 1974 (FERPA) and the Education for All Handicapped Children Act (1975) empowered 
parents by providing them with information and training regarding school curriculum and policies. FERPA gave parents certain rights with respect to their children's educational records, including the right to inspect records, the right to request record corrections, and rights related to requiring parental permission for disclosure of records. The Education for All Handicapped Children Act (1975) gave parents the right to participate in decisions related to the identification, evaluation, and placement of their child with a disability.

In 1983, A Nation at Risk (National Commission on Excellence in Education) identified parent involvement initiatives as a component in restructuring schools and charged parents with the responsibility to participate actively in their child's education. Goals 2000: Educate America Act, the Improving America's Schools Act (P.L. 103-382) of 1994, further supported the development of school initiatives to include parent involvement by advising schools to provide a unified program to involve all parents, and required schools receiving Title I funds to spend a portion of those funds on family involvement programs. Title I, Sec. 1118 (parental involvement) requires each local educational agency to reserve no less than $1 \%$ of their Title I allocation to promote family literacy and parenting skills. Current legislation, The No Child Left Behind Act (2001), reauthorized the parent involvement requirements under Title I.

One theory that emerged in the 1970 s that connected parent and family to the school was Bronfenbrenner's (1979) ecological systems theory. According to this theory, all levels of the ecological system are important and influential in the development of learning in a child. According to Bronfrenbrenner, the major components of the social system include: the microsystem, the mesosystem, the exosytem, and the macrosystem. The microsystem consists of the influences of the immediate environment on the child, 
such as the support the child receives from family and the school that contributes to the learning process. The mesosystem represents the interactions of the school and home; the exosystem is the support of agents outside of school and home; and the macrosystem is the set of beliefs and policies of society (Bronfenbrenner, pp. 22-26). This study examines the impact of the microsystem and the mesosystem on children's reading comprehension.

Studies in the 1980 s provided evidence that children whose parents were actively involved in their educational program attained higher achievement scores than their peers (Henderson, 1987; Rodick \& Hengeler, 1980; Tizard, Shofield, \& Hewison, 1982). Further research on parent involvement also yielded positive results. These included research by Fantussio et al. (1995) that showed higher achievement in math, and research by Zellman and Waterman (1998), whose results indicated that high parental involvement correlated to higher scores in reading. Also, studies by Henderson and Berla (1994) and Henderson and Mapp (2002) concluded that parent involvement is a critical link to children's success at school.

Important research in parent involvement was done by Epstein (1980), a researcher at Johns Hopkins University, who developed a theoretical perspective called the overlapping spheres of influence. This theory emphasizes the similarities and overlap in goals, missions, and responsibilities of schools and homes. The degree of overlap of these spheres of interest between home and school on matters of school work influence the child's motivation to learn. Epstein developed a framework of six types of parent involvement that explains how families can get involved in the education of their children. These types include: (a) parenting; (b) communicating; (c) volunteering; 
(d) learning-at-home; (e) decision making, and; (f) collaborating with the community. Epstein (1992) defined Learning at Home as any activity that provides information and ideas to families about how to help students at home with homework and curriculumrelated activities and decisions, it includes such activities as homework, sharing literature, and writing in a journal. Since then, home-learning has been recognized as a critical element of parent involvement programs, demonstrating a significant relationship to improving the academic achievement of students (Heyman \& Earle, 2000; HooverDempsey et al., 2001; Rodriguez-Brown, Fen Li \& Albom, 1999).

One type of home-learning that includes opportunities for children to interact meaningfully with parents/caregivers is interactive homework. Interactive homework materials are designed by educators to increase parental/caregiver interest in student work and to encourage children to construct their own knowledge within both a social and physical environment (Cooper, Jackson, Nye \& Lindsey, 2001; Hoover-Dempsey et al., 2001). Studies of interactive homework by Bailey, Silvern, Brabham, and Ross (2004) and Bailey (2006) indicate that this type of home-learning can increase both the amount of parental/caregiver involvement and the achievement of the students involved.

In 1995, Hoover-Dempsey and Sandler developed a parental involvement model that addressed why parents/caregivers choose to become involved in their child's education. Because parents/caregivers hold personal efficacy beliefs about their ability to help their children learn, efficacy beliefs will influence parental decisions about the amount of involvement they will exhibit in their children's education. Parents with a strong sense of efficacy are more likely than low-efficacy parents to become involved in their child's education (Bandura, 1986; Hoover-Dempsey et al., 1992). The Hoover- 
Dempsey and Sandler model examined the three major variables central to parental involvement decisions: the role they play in their child's education, parental efficacy, and opportunities for involvement. Research has supported a positive link between the level of parent efficacy and parent involvement (Eccles \& Harold, 1996; Grolnick, Benjet, Kurowski, \& Apostoleris, 1997; Shumow \& Lomax, 2002). Parents who feel more efficacious and who believe in their capability to influence their child's performance will exhibit greater involvement in school related activities.

Bandura (1989) contended that certain efficacy beliefs incorporate knowledge that is specific to the domain of parenting, including the extent to which a parent believes he or she can successfully use knowledge for the betterment of the child. Highly efficacious parents may have a great deal of knowledge concerning the curriculum or the school system and feel capable of helping their child do well in school. Their efficacy beliefs will directly influence certain behaviors and parenting practices that will affect child outcomes (Bandura). For example, if a parent believes that time spent with his or her child working on homework will improve that child's grades, then the parent will spend more time working with the child on homework. Home-learning programs offer the potential to increase the levels of perceived self-efficacy in parents/caregivers, assisting them in becoming more involved in the educational process of their children. By providing a structured program that supports parental involvement, home-learning initiatives may increase the parental belief that they can affect the learning outcomes for students. The current study provided a structured intervention designed to impact parents' beliefs about how they can contribute to their children's outcomes in reading. 


\section{Research Questions}

The following research questions were addressed in this study:

1. Does participation in the home education-learning program (H.E.L.P.) increase perceived levels of parental efficacy among parents/caregivers who participate as compared to those who do not participate?

2. Does participation in H.E.L.P. increase the levels of home learning involvement practices among parents/caregivers who participate as compared to those who do not participate?

3. Are there differences in scores in reading comprehension among children whose parents/caregivers participate in H.E.L.P. as compared to those who do not participate?

\section{The Current Study}

The purpose of this study was to examine if parents/caregivers involvement in a school supported home-learning initiative would improve their perceived levels of selfefficacy and increase their levels of involvement in home-learning activities in the area of reading. The independent variable, the Home-Education Literacy Program (H.E.L.P.), was an initiative designed to provide parents/caregivers of first grade students with detailed instructions in using effective reading comprehension strategies with their children during home-learning activities. The activities aimed to increase the parents'/caregivers' abilities and confidence levels to provide instructional assistance to their children in the home, thus increasing the parents'/caregivers' belief that they are capable of exerting a positive influence on children's school outcomes. 
A total of 146 students from eight existing classes and their parents/caregivers, representing a convenience sample (classes were already established) of eight first grade classes, participated in the study. Four classes ( $n=74$ students) were selected as an experimental group and the remaining four classes ( $n=72$ students) served as the control group. The use of existing groups for control and experimental groups rather than the random assignment of subjects in this study defines it as a quasi-experimental study (Creswell, 2003).

The study examined the effects of a home-learning support intervention program on the perceived efficacy levels of the participating parents/caregivers, as measured by the Parent Perceptions of Parent Efficacy Scale (Hoover-Dempsey et al., 1992) administered on a pre/post basis. The amount and type of parent involvement in the completion of home assignments was determined by means of a locally developed instrument, H.E.L.P. Parent Involvement in Home-learning Scale, also administered on a pre/post basis. The children's reading comprehension was measured by scores on the Brigance Diagnostic Comprehensive Inventory of Basic Skills (Glascoe, 1999) reading comprehension subtest measures pre and post intervention. The next section provides a description of the intervention.

\section{H.E.L.P.}

The Home-Education Literacy Program (H.E.L.P.) was a 12-week home-learning initiative containing 1 week units of interactive homework activities provided to parents/caregivers with the steps necessary to reinforce reading comprehension strategies at home. Each Friday, for 12 weeks, the students took home a work packet containing a grade-level storybook and five detailed assignments with complete instructions for 
parental interaction. Included in each packet was a series of five sequential lessons that dealt with vocabulary, picture walk, predicting, comprehension questioning, and a concluding journal prompt. Materials for the program complemented the skills being taught in the classroom. The intervention also included an orientation packet that instructed families on the use of the program and included parent specific questionnaires. Parents participated in an orientation session on curriculum night, where an explanation concerning the intervention and possible experiences during the coming weeks was provided. Packets were supplied only in English since the number of foreign language students participating in the study was very small (only five families spoke languages other than English). Families were provided with e-mail and telephone contact information for any problems or concerns.

\section{Significance of the Study}

This study addressed several gaps in the current research. First, this study addressed the need for research studies that explore strategies to improve parental efficacy. The current literature supports the notion that parents with higher self-efficacy levels exercise greater involvement in their children's education. These studies clearly demonstrated the relationship that exists between greater involvement and increased student achievement (Ardelt \& Eccles, 2001; Coleman \& Karraker, 2000; HooverDempsey et al., 1992; Turner \& Johnson, 2003). There are, however, few studies that have examined the relationship between parental efficacy and home-learning activities in the area of reading. This study focused on examining the effects of a structured homelearning intervention on student achievement in the area of reading comprehension, while assessing the extent to which the home-learning approach, utilized with the 
parents/caregivers, impacted their levels of self-efficacy. Results from this study will help educators and school administrators determine if structured home-learning approaches can affect student achievement in a specific area and can help to promote the involvement of parents/caregivers in the educational process of their children.

\section{Delimitations}

This research was delimited to the study of first grade students and their parents participating in the H.E.L.P. study and should be generalized to other grades with caution. Academically the study classes were heterogeneously balanced and one teacher was responsible for all academic instruction. The questionnaires were provided only in English due to the small number of limited English proficient parents among the participants. Also, the parent and teacher data were collected by a self reported survey, which may contribute to measurement errors. Further, this study was also delimited because student achievement was measured only by achievement in reading comprehension.

\section{Definitions of Terms}

Home-learning. Home-learning is the involvement of families with their children in learning activities at home including homework and other curricular linked activities (Epstein, 1996).

Home-learning involvement. Parents/Caregivers involvement in monitoring and assisting children with the completion of learning activities in the home.

Parent/Caregiver. Parents, grandparents, step-parents, foster parents, and other adults who provide care for a child. 
Parental efficacy. Parental efficacy is a parent's belief that he or she is capable of exerting a positive influence on children's behavioral outcomes (Hoover-Dempsey \& Sandler, 1995) as measured by the Parent Perceptions of Parent Efficacy Scale (HooverDempsey et al., 1992).

\section{Organization of the Study}

Chapter 1 of this study has introduced the problem, provided a brief overview of the theoretical base, introduced the main research questions, described the intervention that seeks to answer the research questions, and explained the significance of the study. The remaining sections of this dissertation are organized as follows: Chapter 2 contains a review of the literature as it relates to the study. Chapter 3 discusses the research methodology used in the study. Chapter 4 presents the research results. Chapter 5 presents interpretation of the data and recommendations for future practice and research. 


\section{CHAPTER II}

\section{LITERATURE REVIEW}

The theoretical framework of the study comprises several areas of research: research in parental involvement, research in homework/home learning, and research in parental efficacy. This chapter presents a review of the literature in those areas as they are related to this study.

\section{Parental Involvement in Education}

\section{Historical Overview of Parental Involvement in Education}

In the 1960 s, research by educators and behavioral scientists presented evidence that children's early environment could have a deep effect on children's development (Berger, 1981). During this period, programs like Head Start for preschool and FollowThrough for elementary students, were established based on the results of that research. These programs required the involvement of low-income parents in the education of their children as an aspect of participation. At this time, middle- and high-income parents were also being affected by changing social conditions. More women were graduating from college and were entering the workforce. Mothers were becoming equal to the teacher in education level and were taking an active role in decisions about their children's education (Conners \& Epstein, 2006). Families with all levels of education were experiencing new pressures and new opportunities to participate in their children's education.

In 1965, schools began to experience more fully the influence of federal funding. As part of the Elementary and Secondary Education Act (ESEA), Title I funds were 
issued to assist local districts in improving educational services for educationally and economically disadvantaged children. Receipt of these funds was tied to specific requirements, including the development of parental involvement programs. In the 1970s, federal and state legislatures began to include family involvement initiatives in requirements for school improvement (Epstein, 1996). Two very important pieces of legislation with far reaching implications were adopted during this decade. The Family Educational Rights and Privacy Act of 1974 (FERPA) and the Education for All Handicapped Children Act were both signed in November of 1975. FERPA gave parents certain rights with respect to their children's educational records including: the right to inspect records, the right to request record corrections, and requiring parental permission for disclosure of records. The Education for All Handicapped Children Act (1975) gave parents the right to participate in decisions related to the identification, evaluation, and placement of their child with a disability.

Also during this time, several researchers began to explore the importance of parent participation for student academic success. Bronfenbrenner (1979) concluded that connecting home and school practices was important as children make transitions between familial and scholastic experiences. He also developed a connection between a child's ability to read in the primary grades and the existence and nature of school and home ties (Bronfrenbrenner). Research began to clarify parent involvement and the shift toward the concept of school and family partnerships, or more fully, school, family and community partnerships, in order to recognize the shared responsibilities for children within and across contexts (Epstein, 1996). This concept of shared responsibility removed part of the burden from parents to figure out on their own how to become 
involved in their children's education and placed more of the responsibility on the schools to create and maintain programs that foster parent involvement (Epstein, 1996). In 1983, A Nation at Risk (National Commission on Excellence in Education) identified critical components of successful schools. The report directed attention to the need to improve all schools, not just those for students from economically distressed homes and communities. The resultant effective schools movement required schools to restructure to provide a quality education to all students. During the 1980s, schools began to modify their programs and restructure to fit the requirements outlined in A Nation at Risk. This included changes in the content taught in schools, the adoption of more rigorous standards and expectations, more time devoted to learning the New Basics, improved preparation of teachers, and strong leadership from educators, elected officials and the community. A Nation at Risk also identified parent involvement initiatives as a component in restructuring schools and charged parents with the responsibility to participate actively in their child's education.

Goals 2000:Educate America Act, the Improving America's Schools Act (P.L. 103-382) of 1994 (IASA) formalized advances in research and practice. The IASA was a reauthorization of the Elementary and Secondary Education Act (ESEA) of 1965. The ESEA provided funds under Title I to programs for students in the most impoverished schools. The 1994 version of Title I was an improvement over previous versions because of its emphasis on high standards for all children including those who need extra assistance (Epstein, 1996). Prior versions of the law emphasized remedial education. The new law also improved Title I's commitment to family involvement. The law stipulated that families whose children receive Title I services must be integrated with all of the 
other families in a unified school community. Targeted Assistance schools had to provide fully integrated programs of partnership that included all families regardless of eligibility for Title I services. The law also specified that partnerships with families should be linked with student learning. Families needed to understand the academic standards that schools set out for their children, school programs, and the assessments that were used to measure progress. The legislation recognized that basic information helps families become more knowledgeable partners with the schools (Epstein). The law required that schools receiving more than $\$ 500,000$ in Title I funds spend at least $1 \%$ of that allocation on family involvement programs. Under Title I Sec, 1118 Parental Involvement (1) In General the law states:

A local educational agency may receive funds under this part only if such agency implements programs, activities, and procedures for the involvement of parents in programs assisted under this part consistent with this section. Such programs, activities and procedures shall be planned and implemented with meaningful consultation with parents of participating children.

Current legislation, the No Child Left Behind Act (2001), which was signed into law in 2002, continues to stress the importance of involving parents in the education of their children. Educators are encouraged to help parents assist their children with home learning activities, and parents are offered strategies to be effective in the assistance of homework (Cooper \& Gernsten, 2003). 


\section{Theoretical Perspectives of Parent Involvement}

In 1979, Bronfenbrenner proposed his ecological systems theory of partnerships. In this theory various stakeholders share responsibility for the educational achievement of children. Learning of students is supported by a community support structure and requires a partnership of school, student, parents and community members. This theory stated that an individual is a part of a small social system comprising four systems: a microsystem, a mesosystem, an exosystem, and a macrosystem. According to this theory, all the levels of the ecological system are important and influential in the development and learning of the child. The microsystem describes the influences of the immediate environment on the child including the support the child receives from the home or the school to learn. The mesosystem represents the interactions across school and home. The exosystem describes the support of agents outside of school and home that influence the relationship between families and schools. The macrosystem is the set of beliefs and policies of the society that influences all of the other systems (Bronfenbrenner, 1979). The current study explores microsystem and mesosystem effects on student learning in reading comprehension.

In 1980, Joyce Epstein, researcher and director of the Center on School, Family, and Community Partnerships at Johns Hopkins University, developed a theoretical perspective of parent involvement she called overlapping spheres of influence. This theory revised earlier sociological theories that proposed that social organizations are most effective if they have separate goals, missions and responsibilities. Epstein's studies indicated that understanding student learning and development needed an integrative theory that posits that families, schools, and communities are most effective if they have 
overlapping or shared goals, missions, and responsibilities for children. Epstein's model has emerged as the primary framework to study parent involvement.

This theory emphasizes the similarities and the overlap in goals of schools and homes. Epstein discovered in her research that many schools are run like homes and many homes run like schools. Some parents run school-like homes in which children are engaged in learning activities and the children are rewarded for real and objective accomplishments. Likewise, some schools provide a homelike atmosphere. In these schools, student-teacher relationships are important and children are given different opportunities to interact with teachers based on individual needs. According to the theory, the time a child spends in school is influenced by the family and time out of school is influenced by teachers and other school experiences. Epstein's theory is similar to Bronfenbrenner's mesosystem, which comprised the interrelations among two or more settings, such as the relations among home, school and neighborhood peer group. From the results of several of Epstein's studies (1987a, 1987b, 1992) that involved different grade levels and a variety of stakeholders, she (1996) developed a framework of six types of involvement that explain how families can get involved in the education of their children:

Type 1. Parenting. Helping all families understand child and adolescent development and establish home environments that support children as students.

Type 2. Communicating. Designing and conducting effective forms of communication about school programs and children's progress. 
Type 3. Volunteering. Recruiting and organizing help and support for school functions and activities.

Type 4. Learning at home. Providing information and ideas to families about how to help students at home with homework and curriculum-related activities and decisions.

Type 5. Decision-making. Including parent representatives and all families in school decisions.

Type 6. Collaborating with the community. Identifying and integrating resources and services from the community to strengthen and support schools, students, and their families. (Epstein, 1996)

Each type of involvement in Epstein's model requires two-way connections so that schools know and can support their families, and families know and can support their schools. Each type poses specific challenges to schools in the design and implementation of activities. The different types of involvement lead to different results for students, parents and for teachers (Epstein, Coates, Salinas, Sanders, \& Simon, 1997). In the past, the roles of schools and families were seen as separate. Research has indicated the need for a shift in this perspective. This study will focus on activities related to the fourth type of parent involvement, learning at home, to show how this particular type can strengthen parents'/caregivers' behaviors and self-efficacy as well as their children's achievement. Parental Involvement and Student Achievement: Research Findings

Parent involvement has gained significant importance to educators due to the increasing evidence demonstrating its positive relationship to children's success at school. Tizard et al. (1982) studied student achievement in children enrolled in pre- 
kindergarten to second grade. In that study, experimental group students participated in a research program that provided parental support for reading activities in the home. The children were randomly assigned to three groups: a control group, a group that received extra coaching in reading at school, and a group whose parents were trained to listen to them read at home. Because random assignment to groups distributed differences such as student ability, preexisting parental practices, and classroom practices equally across groups, the findings that the home reading group attained higher reading scores at posttest than either of the two other groups was confidently attributed to the parent involvement intervention. The findings of their study revealed that the students in all grade levels who practiced with their parents at home achieved significantly higher scores than the children in the control groups.

In an effort to examine the link between parent involvement and student achievement, Henderson (1987) completed a review of the literature on 49 studies. Based on her analysis, she concluded that the family provides the primary educational environment for children. School-based programs that trained low-income parents to work with their children showed positive effects, including significantly improved language skills, test performance, and school behavior. Her research also concluded that, parent involvement is most effective when it is comprehensive, long-lasting, and well planned. She found that the benefits were not confined to early childhood or the elementary level. There were strong effects from involving parents continuously throughout their children's education. However, involving parents in their own children's education at home is not enough. To ensure the quality of schools as institutions serving the entire community, parents must be involved at all levels in the school. Results also 
indicated that children from low-income and minority families have the most to gain when schools involve parents, and parents do not have to be well educated to positively help their child.

Another study concerning parent involvement and low-income parents was conducted by Yap and Enoki (1994). They sought to identify successful parent practices in Chapter I programs in a Honolulu school district. The majority of the students were Asian or Pacific Islander children from low-income families. Data were collected using surveys and interviews and included parents, students and school staff. The findings indicated that all stakeholders had positive views of parental involvement even though the level of actual parental involvement was determined to be quite low. Involvement tended to be more a home-based activity of reinforcement of concepts. Significant correlations were reported in parental encouragement of reading activities, parents keeping track of student progress, parents preparing a location for study, and parental concern about the students' participation in Chapter I class.

The relationship between parent involvement, parental background, and student achievement was studied by Sui-Chu and Willms (1996). They analyzed data on 24,599 eighth grade students, parents and teachers. Data were provided by the National Educational Longitudinal Study and 12 items were analyzed dealing with aspects of parental involvement. Among these items were: monitoring of homework, discussion with family, limiting T.V. time, limiting outside activities, school contacts, volunteering, and parent teacher organization membership. Findings indicated that the parents who talked with their children about school had children who scored higher on tests of reading and mathematics. Parents who communicated with the school frequently had children 
who scored lower on these tests, reflecting the fact that communication occurs most often when children are perceived to be at risk.

Parent involvement has also been shown to positively affect mathematics achievement. Fantussio et al. (1995) conducted an experiment to examine the effects of parent involvement on mathematics achievement and self-concept. The students in the study, 78 Black fourth and fifth graders, all received the same math instruction. Students were randomly assigned to three groups: students whose parents were involved in a parent involvement program, students whose parents were involved and who also received peer tutoring, and a control group whose students received no intervention. The parent involvement program included parents in three ways. Parents were contacted directly to discuss aspects of their contribution to student learning, they were informed weekly about student achievement, and they could select rewards for their children. Findings indicated that students in both groups with parent involvement showed higher achievement than the students in the control group.

A study that connected parent involvement and reading achievement was conducted by Zellman and Waterman (1998). The study included 193 second and fifth graders and their mothers in Los Angeles. The sample included Latino, White, African American, and Asian children. Most were from two-parent families. Interviews were conducted with mothers, children, teachers, and principals. The measures of parent school involvement were grouped into two categories: school-site involvement and homework involvement. School-site involvement included (a) attendance at scheduled events, (b) participation on a school council board, (c) regular volunteer activity, (d) employment at school, and (e) P.T.A. meetings. Homework involvement included 
self-reported frequency with which parents assisted with homework. The results of this study indicate that parent involvement was lower among single parents and African American and Latino mothers. Findings indicated that high levels of parental involvement correlated positively to higher scores in reading. Also, child I.Q. was a significant predictor of mother homework involvement, with the mothers of higher IQ children demonstrating less involvement. This was attributed to the nature of homework as a form of parent involvement for students who needed extra help. The results imply that homework programs that seek parent involvement need to be designed to involve students of all ability levels, such as the home-learning activities featured in the current study.

Jordan et al. (2000) conducted a study on the effects of an intervention program, Early Access to School Education (Project EASE), designed to provide parents with a theoretical understanding of how to help their children and follow practices to facilitate their early literacy development. Two hundred and forty-eight kindergarten students participated in this study, using an experimental group $(n=177)$ and control $(n=71)$ group design. The school population was primarily White, English-speaking, and not at risk of failure. The participating schools were considered successful in academic achievement based on national standards.

Project EASE required a high level of parent involvement including parental meetings with intervention teachers, training sessions, and the completion of scripted activities at home (Jordon et al., 2000). Parents received information about ways to strengthen vocabulary, extend narrative understanding, develop letter recognition and sound awareness, produce narrative retellings, and understand exposition. Parental 
involvement was measured using self-reporting on surveys, attendance records, and athome book activities. Student outcomes were measured on a battery of language and literacy tests administered to intervention and comparison children prior to the intervention and at its conclusion. Children whose families engaged in the at-school and athome activities made significantly greater gains in language scores as measured on subtests of vocabulary, story comprehension, and sequencing in story telling than the control group children. The greatest gains were made by the low-achieving students in the experimental group, who also reported high home literacy support. The conclusions of the study indicated that parental involvement in early literacy at home and school had a very positive effect on language gains in kindergarteners in a population that was primarily White, literate, and English-speaking. The Jordan et al. study clearly demonstrates the potential impact of home-learning activities with parental involvement on literacy development in young children, which is similar to the focus of the current study. The current study, however, differs in the population participating, and did not require parental participation at school.

Not all studies support a strong link between parent involvement and student achievement. To determine the importance of the connection between parent involvement and achievement, Mattingly, Prislin, McKenzie, Rodriguez and Kayzar (2002) analyzed 41 studies that evaluated K-12 parent involvement programs. Characteristics of parent involvement programs were examined and each article reviewed was coded for more than 100 variables in four categories: (a) program description, (b) context, (c) evaluation, and (d) outcomes. Several important patterns emerged from this analysis. First, the majority of evaluated programs were developed in a top-down manner, with parents, teachers and 
individual schools participating in the design. Second, many evaluations provided very little information about program participants. In those programs that did, a majority of participants were low- income, non-White, and more likely to be mothers than fathers. Thirdly, programs included a variety of intervention components, with $83 \%$ offering more than one type of intervention.

Of the 41 studies Mattingly et al. (1999) evaluated, 20 studies explored the relationship between parent involvement and student achievement, and 15 of these 20 studies used academic data as an outcome measure and evaluated parent involvement in isolation of other interventions. Among the 15 studies that fit these criteria and showed improvement in student outcomes, 10 did not use a control group, so differences in outcome measures may have been related to predictable student learning. Only four studies used matched controls, pretest and posttest, and two of them found that children whose parents received the intervention did not perform significantly better than the students who did not. The researchers found little empirical support for claims that parent involvement programs are an effective means of improving student achievement or changing parent, teacher, and student behavior. Conclusions from this research do not infer that programs are ineffective but rather that serious design, methodological, and analytical flaws in the studies must be addressed before true evaluations can be obtained. The current study uses a quasi-experimental, pre/post design that addresses some of these methodological concerns.

\section{The Middle Class Advantage}

During the past two decades, research in parental involvement has changed with the changing composition and needs of the family. Family structure and the roles of 
family members have changed dramatically (Christenson \& Sheridan, 2001). Today's families can be headed by single parents, unmarried couples, same-sex couples, and teenaged parents. Kellaghan, Sloan, and Alvarez (1993) stated that factors such as the increasing participation of women in the labor force, the instability of marriage, and personal choices of lifestyle have resulted in an increase in the number of families with one or more children but only one parent. As families' composition has changed, it has become necessary to change the types of parental involvement efforts offered to families. With more working parents and single parent households, it is more difficult for parents to go to the school to be involved in traditional ways regarding their children's education.

One early theory that sought to explain the differences in levels of parent involvement between groups of varying socioeconomic levels was reported by Bowles and Gintis (1976). These researchers suggested that there were major structural differences among schools serving students where the majority of students are on free and reduced lunch programs. Schools in lower-income neighborhoods tend to be regimented and controlled by the school administration, and they offer fewer opportunities for parent involvement in decision making. Schools in higher-income areas provide more participatory forms of governance and pedagogy. Bowles and Gintis reported that those differences are related to workplace values and are representative of the varying expectations of teachers and parents from different backgrounds. This middle-class advantage theory implies that parents from lower-income communities are less involved in their schools than are parents from the higher-income communities.

Another theory that helps to explain the differences in the level of parent involvement between economic groups is the theory of cultural capital proposed by 
Bourdieu and Passeron (1977). According to this theory, schools represent and reproduce middle or upper-class values and forms of communication because they embody the values of the predominantly middle-class teachers. These teachers are able to communicate effectively with middle- and upper-class parents who share similar beliefs but have difficulty relating to parents from different economic backgrounds. This bias puts lower-income students and parents at a distinct disadvantage because they must adapt to the dominant culture of the school to meet teacher expectations. This limits the parent involvement opportunities for lower-income groups because the expectations for parent involvement do not match with the community's ability to participate.

Socioeconomic status and level of education were found to have a strong effect on parental engagement in a study by Baker and Stevenson (1986). The researchers interviewed 41 mothers of eighth graders concerning their attitudes and actions on behalf of their child. The findings indicated that parents manage their children's academic careers in ways that have consequences on their academic achievement. For instance, the study found that college educated mothers choose a college preparatory track for their child more often than less educated mothers regardless of the child's academic achievement. This study also found that parents with a college education knew more about the performance of their children academically, had more contact with teachers, and were more proactive in managing the academic progress and achievement of their children.

Lareau (1987) related the notion of cultural capital more directly to parent involvement. She stated that the indicators of cultural capital include the amount of interaction a parent has with other parents, parents' understanding of school processes, 
the amount of contact parents have with school personnel, and the parents' communication skills. Lareau used these indicators in a qualitative study to determine the amount of parental participation in school activities. Results indicated that upper middle-class parents were more likely to be involved, and working-class parents were more likely to be supportive of the school but less likely to be directly involved their child's education. For instance, a parent might support the school P.T.A. decisions, but not attend the meetings or vote on decisions. This study also found that teachers gave higher grades to the children of involved parents, thus influencing levels of student achievement.

Davies (1987) examined the problems facing parent involvement initiatives, including the question of whether parent involvement would increase the already substantial advantages that middle-class parents and children have in educational settings. He determined that existing forms of parental involvement tend to favor greater gains for the middle-class. Choice among schools can be made best by parents with broad experiences and knowledge of the different types of schools available in a district. School improvement council related activities involve setting meetings and agendas, and drafting reports which are all activities familiar to well educated middle-class families. Helping one's child at home with school work may be easier for middle-class individuals who did well in school and are confident and comfortable with regular academic assignments. Organizing to advocate for a cause requires time, money and political skills, which are more often associated with middle-class parents than to those who come from lowerincome levels.

These differences in parental involvement practices between lower-income and middle-class families results in differences in the achievement gap among groups; 
policies and programs must contain certain protections to counterbalance the natural middle-class advantage (Davies, 1987). To counterbalance the middle-class advantage it has been suggested that administrators and teachers must take the initiative to reach out to all parents and to devise a wide variety of ways for them to participate (Davies). Among the suggested strategies are: (a) to have appropriately prepared and sensitive school representatives go into homes to meet with families, (b) having some meetings outside of the school setting in less intimidating and more accessible locations to many parents, (c) using natural and informal settings to reach parents (churches, markets, community centers), (d) preparing materials in other languages for families who are English language learners, and (e) scheduling activities that are attuned to the constituents being sought. Most importantly, Davies stated, "the key point is that for many parents who are poor and from minority and immigrant groups, the initiative has to come from the school, and a diverse and persistent strategy is needed to break down barriers and establish trust" (p.157).

Several researchers (Addington, 1996; Desimone, 1999; McCarthy, 1999) in the 1990s looked at socioeconomic factors and parent involvement. Addington (1996) analyzed data from a large nationally representative sample of students and their parents who participated in the National Educational Longitudinal Studies of 1988, 1990, and 1992. Addington's study found a correlation between parental involvement and high student academic achievement. He also found that family background, including variables such as socioeconomic status, parent occupation and parent level of education, had the strongest effects on parental involvement. Further, parents from higher-income 
backgrounds were more involved with their child's education than those from lowerincome groups.

Desimone (1999) also used data from the National Educational Longitudinal Study of 1988 to examine the relationship between 12 types of parent involvement and eighth grade mathematics and reading scores. The parent involvement types included: (a) discussion with the child about high school; (b) student talks with parents about post high school; (c) volunteering; (d) rules about homework and GPA; (e) P.T.O. involvement; (f) parent attendance at P.T.O. meeting; (g) rules about T.V., friends and chores; (h) parents checking homework; (i) contacting school about academics; (j) students have discussions with parents about school; (k) student talks with father about plans; and (m) knowing parents of child's friends. This study found that parental involvement was a significant predictor of achievement for middle-class and White students, and it was a stronger and more consistent predictor of achievement for the White and the middle-class students than the economically disadvantaged and minority students. Results indicated that a statistically significant difference existed in the relationship between parent involvement and student achievement according to the students' race, ethnicity and family income, as well as according to how achievement was measured (grades, scores) and type of involvement.

There are also differences in the establishment of home-school connections between social classes. McCarthy (1999) synthesized the findings from several studies that described establishment of home-school connections and provided examples of practices that facilitate those connections. Among her findings was a tendency for tight home-school connections for European American, middle-class, students but not for 
students from culturally diverse backgrounds. The studies also determined differences in the amount of literacy materials, the nature of the materials, and the goals for using literacy between middle-class and working-class families. However, all the families both explicitly and implicitly expressed value for literacy activities. An analysis of the practices of elementary teachers also found that reading instruction for diverse populations focused on drill and practice rather than the reading for meaning instruction provided to higher-achieving middle-class students.

Differences in working conditions for lower-income parents can also affect their opportunities for parent involvement. Heymann and Earle (2000) conducted an empirical study to determine if low-income working parents face significantly different nonfinancial barriers (such as no paid leave or flex time) to parental involvement in the form of direct interaction with their children's schools and teachers than those faced by higherincome working parents. They examined the working conditions faced by parents who had at least one child who was in need of help because of educational or behavioral problems. The study analyzed data from the National Longitudinal Survey of Youth, Mother and Child Surveys for 1,878 families where mothers worked more than 20 hours per week. Results indicated that parents of low achieving students were significantly more likely to lack paid leave or flexibility that they might use to meet with teachers, visit schools, and help address their children's problems. Nationwide, low-income parents were more likely than middle- and upper-income parents to lack the flexibility they needed to help with academic and behavioral problems.

The research reviewed in this section establishes a link between parental involvement practices and socioeconomic factors. The families that were involved in the 
current study are primarily from lower-income groups. One purpose of the current research was to provide an intervention that could overcome some of the difficulties in providing access to parental involvement in the area of home-learning for these families.

\section{Homework/Home-learning}

\section{Homework and Achievement in Reading}

Homework has been a part of American education since the beginning of formal schooling in the United States. It has been widely accepted in some time periods and rejected in others by both educators and parents (Cooper \& Gernsten, 2003). In 1983, the report by the National Commission on Excellence in Education, A Nation at Risk, placed new emphasis on homework. This document reported that U.S. students were spending less time doing homework than students in other countries. This report reopened the debate among the various stakeholders in public education. Business and community leaders asked educators to revisit public school homework policies in fear of losing our national competitive edge against other nations.

Since then, research has sought to determine if homework is effective in improving student achievement. Epstein (1988) collected data from 82 teachers and 1,021 students and their parents in a study to examine the correlates of homework activities and elementary school students' achievement and school behavior. Results indicated a negative correlation between the time spent on homework and student academic achievement in reading. This is not to say that time spent on homework affects achievement negatively; rather, students with lower achievement tend to spend more time doing homework, a relationship that might be caused by teachers and parents providing more homework time for weaker students. In another study, Epstein (1991) used 
longitudinal data from 293 third and fifth grade students in Baltimore. The research examined the relationship between parental involvement practices, including homework, and the students' test scores in reading and math on the California Achievement Test in the 1980-1981 school year. Results of this study revealed a positive relationship between parent involvement in homework and reading.

In 1989, Cooper completed a review of 120 studies on the effects of homework. Cooper found that the conclusions of the studies suggested positive and negative effects of homework. Among the positive effects was that homework had an immediate impact on the retention of the material it covered. It was also suggested that homework improved students' study skills and attitudes towards school. Additional potential benefits were that homework could foster independent and responsible character traits and could involve parents in the educational process. The findings also indicated that homework had a positive effect on academic achievement but the effect varied by grade level. For high school students, homework had positive effects. However, no significant positive effects were observed for elementary students. Additionally, the amount of homework correlated differently with achievement based on grade level. For high school students, indications were that more homework was highly correlated with more achievement. In middle school, achievement continued to improve until assignments lasted between one and two hours a night, after that the positive relationship diminished. Elementary students again had no improvement in achievement based on increased amounts of work. Some of the negative effects of homework for elementary students included: loss of interest in academic material, physical and emotional fatigue, and confusion of instructional technique. 
A study that sought to determine how much homework time is optimum for student achievement was conducted by Easton and Bennett (1990). They collected data on a sample of students attending 30 elementary schools in Chicago. The students selfreported by questionnaire how many days a week they were assigned homework and how much time they spent in the completion of assignments. The data were compared to student gains measured on the Iowa Test of Basic Skills. Results of the study indicated a strong relationship between the amount of time reported spent on homework and student achievement.

To investigate connections between parent involvement, homework, and student achievement, Keith, Troutman, Trivette, Keith, and Singh (1993) used the data from the National Educational Longitudinal Study of 1988 to examine the impact of parental involvement in the achievement of eighth grade students. Findings of the study indicated that parental involvement was beneficial for the academic achievement of students in all subjects. Positive correlations were found between the completion of homework and parental involvement. The study further found that previous achievement was also correlated with parental involvement. Indications were that the parents of students who did well were more involved and this involvement produced higher achievement.

Kincheloe (1994) looked at the effect of directed parent involvement in student homework on student achievement. His study involved 28 volunteering high school students enrolled in a pre-calculus class. The students were randomly assigned to experimental or control groups. The parents of the experimental group received a packet of material aligned with the course content, a form to record student sessions, a return envelope, and instructions. The only contact from the instructor was one phone call to the 
parents. At the end of 2 weeks, student achievement was measured on a unit test. Data analysis showed a moderate correlation between the amount of parental involvement and student scores.

In a comprehensive meta-analysis, Cooper, Robinson, and Patall (2006) summarized the results of research on the effects of homework that were conducted over the period from 1987 to 2003 in the United States. They found that within and across design types there was generally consistent evidence for a positive influence of homework on achievement. They examined 69 correlations between homework and achievement reported in 32 documents. Fifty correlations were in a positive direction and 19 in a negative direction. This included six studies employing an exogeneous employment of homework. "This meant that the presence or absence of homework assignments was manipulated expressly for the purpose of the study" (Cooper et al., p. 13). The six studies that employed exogeneous manipulation all revealed a positive effect of homework on unit tests. It was determined that studies that reported simple homework achievement correlations revealed evidence that a stronger correlation existed in grades 7-12 than in grades K-6. The reviewers offered several suggestions to explain this grade level association: (a) younger children are more easily distracted by stimuli in the home; (b) younger students have less effective study habits; (c) evidence suggests that teachers assign homework in the early grades to develop young students' time management, a skill not measured on standardized test; and (d) there is evidence that young children struggling in school take more time to complete assignments. Joseph Simplicio (2005), in his commentary on homework in the new millennium, finds the controversy about homework and its use to be widespread and 
active in the contemporary media. He stated that when used properly, studies have repeatedly shown that homework, from the elementary through the university level, is an effective method for reinforcing educational learning goals. He reviewed studies that were conducted by educators working at all levels and in all areas of education and concluded that there is a positive correlation between homework and higher levels of student academic achievement. Despite these findings, Simplicio discovered concerns about the amount of time students should be required to spend on this activity and the quality and usefulness of the assignments. As our nation comes to the end of the first decade of the $21^{\text {st }}$ century, the debate on homework and its effectiveness continues.

\section{Parent Involvement in Homework/Home-Learning}

In a 1995 study, Hoover-Dempsey, Bassler, and Burow examined how homework related to formal learning. The researchers questioned how parents thought about their roles and activities in relation to children's school assignments and homework success. Parents of 69 students in elementary school were questioned in interviews about how they conceptualized their roles in relation to homework performance and how they helped their children to complete homework. Findings suggest that students' homework represented a complex and multi-dimensional set of tasks for parents, for which they often felt ill-prepared by both limitations in knowledge and competing demands for their time and energy.

This Hoover Dempsey et al. (1995) study implied that parents' involvement in homework was based on their understanding of their children's characteristics and their own abilities. They saw themselves as having an active role to play in their children's homework and described their role as including the structuring of homework activities, 
motivating children, working with them in varied tasks, and interacting with the teacher about homework and suggestions for help. Most of the parents derived strong personal meaning from their efforts to help their children: their successes and failures in helping with homework were important to them, and they seemed to consider successful efforts a significant part of being a "good" parent.

Based on their study, Hoover-Dempsey et al. (1995) developed a definition of homework and homework-related activity as described by parents. This definition involved several areas of school-related work carried out at home or outside of the normal school day. These were (a) activities that parents engage in at home with or for the child in relation to assignments given; (b) parents' plans and activities related to the child's accomplishment of assignments brought from school; (c) parents' interaction with the child about the school day's activities and work (including checking over papers); (d) parents' interaction with others at school, in the family, or in other settings related to the child's assignments; (e) parents' observations related to children's accomplishment of school-related assignments at home; (f) parents' observations about themselves and their activities related to supervising, helping, or interacting with their children about school assignments; and (g) parents' observations concerning the importance of their own or their children's involvement in school assignments or related activities carried out at home. The current study sought to improve parents' involvement in the area of homelearning (homework).

In a review of research on parental involvement in student homework, HooverDempsey et al. (2001) focused on understanding why parents become involved in their children's homework, which activities and strategies they employ in the course of 
involvement, the influences on student achievement from their involvement, and which student outcomes are influenced by parents' involvement. The researchers' findings suggest that parents involve themselves in student homework because they believe that they should be involved, believe that they can make a positive difference, and that their children's teachers want them to be involved. Parent involvement operates largely through modeling, reinforcement, and instruction. Parents' homework involvement appears to influence student success by supporting student attributes related to achievement such as attitudes about homework, perceptions of personal competence, and selfregulatory skills (Hoover-Dempsey et al.). The current study involved parent homework involvement intended to promote student achievement in reading.

Cooper (2001) tested a model of the influence of homework on classroom performance using a sample of 428 students in grades two to four, their parents, and 28 teachers. The researchers used structural equation modeling (SEM) to examine relationships among variables. Structural equation modeling is a statistical technique for testing and estimating causal relationships using a combination of statistical data and qualitative causal assumptions (Kline, 2004). Results indicated that positive student homework completion rates, higher student ability, and positive parent attitudes toward homework were all related to greater parent facilitation (help with homework). Classroom grades were unrelated to students' attitude toward homework but were predicted by how much homework the student completed, student ability, and the amount of parent facilitation. Cooper's data revealed the critical role of parents in both the homework process and in the success of elementary school students. Positive parent involvement in homework was the strongest predictor of grades. Positive parental attitude 
toward homework not only predicted amount of parent facilitation but also directly related to students' attitude toward homework.

Fishel and Ramirez (2005) reviewed 24 studies of parent involvement for schoolage children conducted between 1980 and 2002. They evaluated them in accordance with criteria developed by the Task Force on Evidence-Based Interventions in School Psychology (including randomization, reliable outcome measures, control group, effect size, etc.). All of the studies involved parental involvement with home learning, with most targeting a change in academic performance, including reading skills, mathematics skills, spelling, and homework completion. The strongest evidence for parent involvement was provided for programs that implemented parent tutoring in the home and targeted a single academic problem of elementary school-aged children, primarily reading or mathematics.

In a meta-analysis of 41 studies involving parental involvement and academic achievement of urban elementary school children, Jeynes (2005) determined that the relationship between parental involvement and student achievement holds for overall measures of parental involvement and for most specific components of parental involvement. The study's results indicate a considerable and consistent relationship between parental involvement and academic achievement among urban students. This also holds when disaggregated by gender and racial minority status. "That the relationship between parental support and educational outcomes held across race is particularly important for educators and parents in an increasingly diverse country" (Jeynes, p. 263). Jeynes further felt that these results were encouraging because they indicate that parental involvement might be one means of closing the achievement gap. 
In 2004, researcher Marya Granda conducted a study of two projects that provided home-learning literacy materials to parents for use with their children. One project involved first grade students and their parents and the second involved second and third grade students and their parents. Children brought home materials to share reading experiences with their family members. Instructions on use and care of materials were provided to the students prior to distribution of the materials. The literacy bags for first grade children contained activities like sight word bingo, picture books, and file folder games. The bags also contained parent feedback journals and materials to enrich parental literacy practices. Literacy bags for second and third grade students contained literature, graphic organizers and notebooks as well as parent feedback journals. The literacy bags were sent home for a one week period and many students had an opportunity to take them home twice in the year.

Data collected in the Granda (2004) study included self-report surveys from parents that asked questions about their knowledge of both grade-level expectations and literacy activities that could be conducted at home to help their child's literacy development. Students' writing samples were collected to provide teachers with an informal assessment of the students' writing ability. Parent feedback journals were used to provide constructive criticism on the literacy bag's activities, relate concerns regarding the child's performance in relation to state standards, and describe experiences that the parents had with the literacy bags. Results indicated that these programs were successful in several areas. The findings reinforced the idea that home-learning activities can be enjoyed by both parents and their children and at the same time be beneficial to both. Home literacy materials were shown to be an effective tool to communicate grade-level expectations to 
parents. Results also indicated that home literacy materials can be used to make parents more aware of the types of literacy activities that can be carried out at home to increase their child's skills. This study is similar to the current study because Granda was also attempting to improve student reading achievement through the use of home literacy materials and parent/child interaction. The current study is similar, but is for a 12 week time period rather than the 1 week, and H.E.L.P. used more formal assessment than Granda's study did.

A parent involvement study that also concerned the effects of interactive homework was conducted by Bailey et al. (2004). They studied the effects of interactive reading homework and parent involvement with children during homework on students' achievement in inferential reading. Interactive reading homework refers to homework designed to involve both parents and children and to facilitate student reasoning. The researchers employed homework that was designed by teachers to effectively provide opportunities for children to interact meaningfully with parents. The participants were 84 parents and 84 second grade students. Data were gathered from students' pre and posttests on inferential reading, parent behavior checklists, and parent homework questionnaires. The results indicated that interactive homework increased both parental involvement during the completion of the reading homework assignments and the students' ability to draw inferences. Some of the elements of that study parallel the current study, but H.E.L.P. concentrated on first grade students and reading comprehension skills.

Bailey (2006) reported on the results of an interactive homework program that was developed to improve student scores on the SAT9. The student population that was 
served was determined to be "at-risk readers" or readers who are at risk of failing school because of reading deficiencies. The report examined whether parent training to increase parent-child interactions during the completion of interactive homework assignments facilitate increases in a student's ability to draw inferences from reading selections. This program provided parents with a 4 week training period in which they were instructed in the use of interactive homework with their child and provided with research that focused on reading strategies. They also participated with interactive homework that was designed to increase parent involvement with their child. Results of this study indicate that this type of program has the potential to improve academic performance for academically at-risk students.

Research in homework/home-learning has shown promising results in improving student achievement. The current study uses an interactive parent involvement homelearning program that involves parents/caregivers in direct instruction of their children in the area of reading comprehension. Unlike these studies, H.E.L.P. concentrated on first grade students in a multi-cultural setting, provided an intervention for 12 weeks, and utilized assessment in the area of reading comprehension.

\section{Parental Efficacy}

The theoretical concept of expectations and their effect on behavior was studied by Bandura (1977) within the context of social learning theory. Bandura defined two types of expectations: Type I, or outcome expectations, and Type II, or efficacy expectations. Outcome expectations are anticipations that certain behaviors will lead to certain outcomes. Efficacy expectations deal with the belief that one is capable of performing in a particular way. Individuals will avoid certain tasks and situations if they 
believe them to exceed their capabilities. Likewise, individuals will undertake and perform activities they feel capable of handling (Bandura). For example, in Type I, students who expect to be rewarded for good grades have positive outcome expectations and will probably work hard for good grades. In Type II, even though the student perceives that rewards will follow good grades, if one does not believe that one can perform well enough to get the good grades, one will not be motivated to try.

Efficacy expectations affect whether individuals initiate responses, how much effort they expend on them, and whether they persist when faced with obstacles (Bandura, 1977). If a person believes that one can successfully complete a task, one will put forth the effort necessary to complete the task. One will also persist even in the face of some difficulty and will probably choose to complete similar tasks or even more challenging tasks of the same structure. The concept of self-efficacy can therefore be used to help explain the individual's behaviors and motivations concerning the completion of tasks.

Bandura (1989) posited that certain parental efficacy beliefs incorporate knowledge that is specific to the domain of parenting, including the extent to which a parent believes he or she can successfully use knowledge for the betterment of the child. Highly efficacious parents may have a great deal of knowledge concerning the curriculum or the school system and feel capable of helping their child do well in school. Their efficacy beliefs will directly influence certain behaviors and parenting practices that will affect child outcomes. For instance, if the parent has knowledge in mathematics, the parent will feel more competent helping a child complete mathematics homework and will more likely choose to work on that homework with the child. 
Bandura (1980) also theorized that efficacy should be examined from a taskspecific approach. In this approach, self-efficacy beliefs are one aspect of a larger system that may change in response to the demands and requirements of a task, the situational factors concerning a task, and the specific intrapersonal factors related to accomplishing a task. For instance, parents may feel efficacious in his ability to help their children with one kind of homework, but lack efficacy in helping at other types of tasks. The requirements of the task may influence how successful individuals feel they can be when tasks and task requirements are always changing.

Harter (1978) proposed another theory of efficacy as a more global trait. He suggested that individuals develop this general type of efficacy by being successful in various achievement situations throughout their lives. This broad type of efficacy is applied to other situations the individual encounters, including parenting. Studies (Shelton, 1990: Watt \& Martin, 1994: Woodruff \& Cashmere, 1993) have found that general self-efficacy does predict experiential variables including more global parenting qualities, more effective experiences, and more task-specific self-efficacy beliefs. This more global view of self-efficacy may include any number of domains including parenting, mathematics, language arts, science, or liberal arts. If individuals have generally been successful in one area, they may also believe that they can be as successful in another area. Harter also contended that parental efficacy, as well as other domains beyond academics, may be judged by measuring individuals' general selfefficacy because their general belief about their ability to achieve transcends most aspects of their lives. Several other studies have supported Harter's work. Researchers have found that general self-efficacy does in fact predict certain experiential variables such as 
more task-specific self-efficacy beliefs, more global parenting qualities, and more effective experiences (Shelton; Watt \& Martin; Woodruff \& Cashmere).

Bandura (1989) viewed self-efficacy from a task-specific point of view. Selfefficacy can also been examined from a more domain-general or domain-specific view (Coleman \& Karraker, 2000). General efficacy describes an individual's feelings for achievement across all aspects of his or her life. In a domain-general approach, efficacy beliefs are specific to one particular domain. In this approach, a domain such as parenting can be broken down into several task-specific parts. Coleman and Karraker (1998) suggested several categories of task-specific parental efficacy beliefs including facilitation of a child's cognitive development. This category would include a parent's ability to assist with school work. The current study is concerned with a parent's perceived efficacy to support home-learning activities that improve a child's reading comprehension.

Several researchers have examined the relationship between parental involvement and parent efficacy (Eccles \& Harold, 1996; Hoover-Dempsey et al., 1992; HooverDempsey \& Sandler, 1995, 1997; Reed, Jones, Walker \& Hoover-Dempsey, 2000). Hoover-Dempsey et al. (1992) conducted a study involving the parents of elementary school children and their teachers. They based their study on personal self-efficacy work by Bandura. In the study, parents were administered self-report measures of domain specific parental efficacy and parental involvement behaviors. Teachers were also administered self-report measures of their own efficacy, their perceptions of parental efficacy for their students' parents, and estimates of parental involvement behaviors. Results indicated a positive relation between parental efficacy and parental involvement. 
The parents who believed themselves to be more capable of assisting their children in academic areas also tended to volunteer at school and engaged in other educational activities with their child. The study also indicated that teacher perceptions of parental efficacy and estimates of parental involvement were also significantly correlated. Teachers who believed that their students' parents influenced their learning also believed that the parents were more involved. The data led to the conclusion that parental involvement was related to teacher perception as well as teacher perception being related to the level of parental involvement.

Hoover-Dempsey and Sandler (1995) developed a parent involvement model that stressed the reasons parents choose to become involved in children's education. They developed a three tiered model that suggests that parents become involved primarily because (a) they have developed a personal construction of the parental role that includes participation in their children's education, (b) they have developed a positive sense of efficacy for helping their children succeed in school, and (c) they perceive opportunities or demands for involvement from children in school (Hoover-Dempsey \& Sandler). The model suggests that parental involvement then influences children's developmental and educational outcomes through such mechanisms as modeling, reinforcement, and instruction, as mediated by the parent's use of developmentally appropriate activities and the fit between parental activities and the school's expectations (Hoover-Dempsey \& Sandler, 1995). The major outcomes of this involvement process are the child's development of knowledge and skills and the child's personal sense of efficacy for succeeding at school. 
Other researchers also sought to connect parental efficacy to parent involvement. Eccles and Harold (1996) conducted a study with mothers and their early adolescent children that included both elementary and middle school students. The study focused on how parental efficacy relates to certain parenting behaviors including parental involvement in school. Included in this study were both general and specific measures of self-efficacy. These measures were used to determine how capable parents felt in assisting students with school work. The study utilized self-report questionnaires that included both domain-general and domain-specific parental efficacy measures, questions of parental involvement in school, and questions concerning adolescent performance and adjustment. The study results indicated that domain-general efficacy was positively related to school involvement. Parental involvement was found to be predictive of better academic performance and a better adjusted child. Parents who believed in their capability to influence their child's performance were more involved in school related activities, the child performed better in school, and had a more positive school experience. Related to the current study, Eccles and Harold found that mothers' involvement in their child's reading achievement was positively related to their own confidence in their ability to help their child with language arts work (efficacy, $r=.31$, $p<.01)$.

Another study that looked at the factors related to parental involvement was a study by Grolnick et al. (1997) of 209 mothers, their third to fifth grade children, and 28 teachers. Three sets of factors were identified: (a) parent and child characteristics including efficacy, (b) family context, and (c) teacher behavior and attitudes. Parents, teachers, and children reported on three types of involvement: school, cognitive, and 
personal. Data were obtained through self-report questionnaires. Results of this study determined that mothers who felt efficacious, who saw their roles as that of teacher, and who viewed their children as less difficult, were more involved in cognitive activities. Parents expressing a greater and more efficacious role of parents tended to be more active in all three types of involvement.

Research has also sought to investigate the relationships between parental efficacy, parenting behaviors, and student outcomes. Shumow and Lomax (2002) conducted a study with a large, stratified sample of parents and their adolescent children. Interviewers collected data via telephone from both parents and their adolescent children. Measures included questions concerning socioeconomic status, neighborhood environment, domain-specific parental efficacy, parental involvement, parental monitoring, and outcomes related to grades and behavior. For the overall sample, neighborhood quality predicted parental efficacy, parental efficacy predicted reported parental involvement and monitoring, both of which predicted the academic and social emotional adjustment of adolescents. This study provides a link between parental efficacy, parenting behaviors, and student outcomes, the constructs examined in the current study.

Brody, Flor, and Gibson (1999) extended the knowledge relating to maternal efficacy beliefs, parenting practices, child competence, and specific variables that may have mediated the relationship between mothers and children. The study included singlemothers and their 2 to 9 year old children. The mothers were given self-report questionnaires reflecting parental efficacy beliefs in both domain-specific and domaingeneral ways. The questions concerned competence promoting practices including: 
warmth, supportiveness, and consistency in routine; ratings of developmental goals for their child; and adequacy of financial resources. Quality of the mother-child relationship was rated by the researchers' observation. Teachers of the children also rated the level of involvement of the mother. A composite measure of parenting practices was created from these three sources. Children were administered a self-report measure of self-regulation and two subscales from the Woodcock-Johnson Psycho-Educational Battery Revised (Woodcock \& Johnson, 1990). Teachers were asked to rate the psychosocial competence of the children in question.

Results in the Brody et al. (1999) study indicated that parental efficacy beliefs regarding education and communication were related indirectly through developmental goals. This suggested that efficacy beliefs affect motivational processes including goal setting. This goal setting might influence certain behaviors. Parents, who reported feeling efficacious toward parenting, adopted particular beliefs about their child's development and set goals accordingly. Based upon these goals, the more efficacious parents assumed more competence promoting parenting practices. These positive parenting practices influenced the student's competence in both academic and social situations.

In the current study, parents participated in a home-learning program that provided them with direct knowledge and practice of the school curriculum in reading. By increasing the parents' knowledge of the reading process and providing them with the tools to better assist their child with home-learning activities it was predicted that their perceived self-efficacy would improve. 


\section{Summary}

The review of literature indicates that parental involvement is an important component of effective schools. Government legislation including Goals 2000:Educate America Act, the Improving America's School Act of 1994, and No Child Left Behind all require schools to include parental involvement programs in their planning. Parent involvement has been linked by research to student achievement in both reading and math. In 1980, Learning at Home was identified by Joyce Epstein as one area of parental involvement that could impact student achievement. Since that time, home-learning has been recognized as a critical element of parent involvement programs. Interactive homelearning includes opportunities for children to interact meaningfully with parents, and this type of home-learning can increase both the amount of parental involvement and the achievement of students.

One aspect of parenting that affects parental involvement is parental self-efficacy. Parents/caregivers hold personal efficacy beliefs about their ability to help their children learn. Research indicates that parents with a strong sense of efficacy are more likely than parents with low efficacy to become involved in their child's education. Studies have supported this link between the level of parent efficacy and parent involvement. Homelearning programs offer the potential to increase the levels of efficacy in parents by providing a structured program that supports involvement. This, in turn, can lead to greater academic achievement on the part of their children. 


\section{CHAPTER III}

\section{METHODOLOGY}

The purpose of this study was threefold. First, it sought to determine if participation in a home education learning program would impact the perceived levels of parental efficacy among parents/caregivers. Second, it investigated if participation in this program would increase the levels of home learning involvement practices among parents/caregivers who participate in the completion of home-learning assignments. Finally, it sought to investigate if one practice of parent involvement, completion of interactive home-learning assignments, affected the reading comprehension achievement of first grade students. This chapter will present the context, participants, procedure, methods of data collection and data analysis.

The methods used in this study are primarily quantitative and experimental as described by Hittleman and Simon (2002). Hittleman and Simon identify the three main purposes of quantitative research: to describe, to compare, and to attribute causality. They state that in experimental research, the researchers' purpose is to draw conclusions about the influence of one or more variables on another variable. They further state that in experimental research, researchers set out to answer questions about causation. In experimental research, the researcher will wish to attribute the change in one variable to the effect of one or more other variables. In this study, the researcher explored the impact of one variable, a home-learning intervention program, on the perceived efficacy levels of parents, the level of parental involvement in home learning, and reading comprehension scores of first grade students, indicating an experimental design. However, the use of 
existing groups for control and experimental groups rather than the random assignment of subjects in this study further defines it as quasi-experimental (Creswell, 2003).

\section{Setting and Participants}

The study was conducted in a rural school district in the southern U.S. that is growing rapidly and is feeling tremendous pressure from the influx of new students from diverse backgrounds. The general population has doubled from 1980 to 2000, and it is projected to triple between 1980 and 2010 (Emory University Strategic Planning, 2004). The school is located in a county with a low rate of high school completion of $45 \%$ and a high illiteracy rate of 23\% ( Emory University Strategic Planning). During the 2005-2006 school year, the county reported a district school population that was $51 \%$ economically disadvantaged (Georgia Department of Education, 2007). Ethnically, the student population was 1\% Asian, 44\% Black, 4\% Hispanic, 3\% multiracial, and 48\% White. In addition, $2 \%$ of the students were limited English proficient (LEP), and 14\% were identified as having a disability (Georgia Department of Education). Table 1 shows a comparison of state, county, study school, and study population data indicating percentages of students in each category.

In the 2006-2007 school-year, the county operated 20 schools including twelve elementary schools containing grades Pre/K-5, four middle schools grades 6-8, three high schools grades 9-12 and one alternative school grades 7-12. More than 19,000 students were enrolled in the county (Newton County Public Schools, 2008). Over the past 8 years, 9 new schools and 57 additional classrooms have been constructed (Newton County Public Schools). During that time period, massive renovations have been made to the existing schools to provide updated structures and technologies. 
Table 1

Comparison of State, County, School, and Study Populations by Percent of Population

\begin{tabular}{|c|c|c|c|c|}
\hline Characteristic & State $\%$ & County $\%$ & School \% & Study $\%$ \\
\hline \multicolumn{5}{|l|}{ Race/ethnicity } \\
\hline Asian & 3 & 1 & 1 & 2 \\
\hline Black & 38 & 44 & 60 & 61 \\
\hline Hispanic & 8 & 4 & 3 & 2 \\
\hline Multiracial & 2 & 3 & 6 & 5 \\
\hline White & 48 & 48 & 30 & 30 \\
\hline Having a Disability & 12 & 14 & 12 & 13 \\
\hline $\begin{array}{l}\text { Economically } \\
\text { Disadvantaged }\end{array}$ & 50 & 51 & 64 & 66 \\
\hline LEP & 5 & 2 & 1 & 0 \\
\hline
\end{tabular}

Source: Georgia Department of Education, 2007.

The school where the current study took place had approximately 825 students (2007) in grades K-5. The school has grown steadily over the past few years from a population of 630 in 2003 . On the state criterion referenced competency test administered in spring $2006,17 \%$ of the state's tested children did not meet minimum competency requirements in reading. The county rate was $19 \%$ below minimum competency in reading, and the school had $34 \%$ of its children below minimum competency. Twelve classes were located in trailers outside of the main building. 
To provide heterogeneous balance in the classes at this school, students are divided by gender, race, and ability and distributed evenly into classes. In each class, one teacher is responsible for all academic instruction. The school uses a controlled scripted curriculum in reading, uniform scheduling, and group planning. In this intervention, the experimental group received home-learning packets sent home weekly with the children (the independent variable) and participated in a parent orientation program. The four classes determined to be in the control group received the regular homework assignments commonly used by teachers. Permission to conduct this study was received on a district level from the Superintendent of Schools and on a school level from the building principal. Formal exempt approval from the Institutional Review Board was obtained from Florida International University. A copy of the approval memo is provided in Appendix A.

\section{Families}

A total of 146 students and their parents/caregivers representing a convenience sample of eight first grade classes participated in the study. Four classes $(n=74)$ were selected as an experimental group, and the remaining four classes $(n=72)$ served as the control group. The sample included 89 Black (61\% of the sample), 44 White (30\%), 3 Hispanic (2\%), 3 Asian (2\%) and 7 multi-racial students (5\%). There were 72 girls in the sample and 74 boys. The mean age for the group at the beginning of the study was 6.6 years. There were 19 students included in the study who were identified as students with disabilities (13\% of the sample), including specific learning disabilities, emotional behavioral disorders, and other health impairments. The sample contained 96 students (66\% of the sample) who were determined by free lunch eligibility to be economically 
disadvantaged. Family demographic information was analyzed using chi-squares for demographics and $t$-tests for age to determine the equivalence of the experimental and control groups.

For analysis, the racial/ethnic categories Hispanic, Asian and Mixed were combined into one category because of the small number of students in each of those categories. The resulting distribution is displayed in Table 2. A Pearson chi-square was used to compare the experimental group and the control group to establish equivalency $X^{2}(2, N=146)=0.34, p=.844$. These results indicate that the two groups were not significantly different in racial/ethnic composition at the .05 level.

Table 2

Comparison of the Subjects from Project H.E.L.P. by Racial/Ethnic Category for the Experimental Group and the Control Group

\begin{tabular}{lcccccc}
\hline Racial/Ethnic & \multicolumn{2}{c}{ Experimental Group $(n=74)$} & & \multicolumn{2}{c}{ Control Group $(n=72)$} \\
\cline { 2 - 3 } \cline { 5 - 6 } Group & No. & $\%$ & & No. & $\% 2.5$ \\
Black & 4 & 59.5 & & 45 & 30.6 \\
White & 23 & 31.1 & & 22 & 6.9 \\
Other & 7 & 9.5 & & 5 & \\
\hline
\end{tabular}

The groups were also compared by gender. The number and percentage of each gender by group is displayed in Table 3. A Pearson chi-square analysis was used to establish equivalency in gender for the two groups, $X^{2}(1,146)=0.10, p=.747$. These results indicate that the two groups were not different by gender.

To compare the two groups in age a t-test was run on the collected age data for the two groups: experimental group $(M=0.47, S D=5.61)$ and control group $(M=6.65$, 
$S D=0.45)$. The results of the t-test, $t(144)=0.42, p=.672$, indicated that the groups were not different in age at the beginning of the study.

Table 3

Comparison of the Subjects from Project H.E.L.P. by Gender for the Experimental Group and the Control Group

\begin{tabular}{lcccccc}
\hline \multirow{2}{*}{ Gender } & \multicolumn{2}{c}{ Experimental Group $(n=74)$} & & \multicolumn{2}{c}{ Control Group $(n=72)$} \\
\cline { 2 - 3 } \cline { 5 - 6 } Female & No. & $\%$ & & No. & $\%$ \\
Male & 40 & 54.1 & & 37 & 51.4 \\
& 34 & 45.9 & & 35 & 48.6 \\
\hline
\end{tabular}

Teachers

Teachers participating in the study initially completed the Teacher's Family Involvement Practices Survey (Garcia, 2004) and the Family Involvement Teacher Efficacy Scale (Garcia, 2004) to control for teacher variation related to parental involvement practices. This surveys generated data in three different areas: demographic information, teacher efficacy in the area of family involvement (Family Involvement Teacher Efficacy Scale) and teachers' practices regarding parent and family involvement (Teachers' Family Involvement Practices Survey). Based on these data, classes were assigned to either the experimental or control group to ensure equivalency among the teachers working with each group.

Demographic information included ethnic origin, gender, years of teaching experience, and highest degree earned (see Table 4). Of the eight participating female teachers, four were Caucasian and four were African American, and there were equal numbers of each in each group, experimental and control. The teachers in each group 
averaged $10+$ years in teaching. Three teachers in each group had completed a BA/BS in education and one teacher in each group held an advanced degrees in education.

Table 4

Teachers’ Demographic Information by Group Assignment

\begin{tabular}{clcc}
\hline \multicolumn{1}{c}{ Teacher } & \multicolumn{1}{c}{ Race } & Years Teaching & $\begin{array}{c}\text { Highest } \\
\text { Degree }\end{array}$ \\
\hline $\begin{array}{c}\text { Experimental } \\
\text { Group } \\
\text { Teacher 1 }\end{array}$ & Caucasian & $16+$ & BA/BS \\
Teacher 2 & Caucasian & $16+$ & MA/MS \\
Teacher 3 & African American & $1-3$ & $\mathrm{BA} / \mathrm{BS}$ \\
Teacher 4 & African American & BA/BS \\
\hline Control Group & African American & $16+6$ & $\mathrm{Ed} . \mathrm{S}$. \\
Teacher 1 & African American & $10-15$ & $\mathrm{BA} / \mathrm{BS}$ \\
Teacher 2 & Caucasian & $7-9$ & $\mathrm{BA} / \mathrm{BS}$ \\
Teacher 3 & Caucasian & $7-9$ & $\mathrm{BA} / \mathrm{BS}$ \\
Teacher 4 & & & \\
\hline
\end{tabular}

Note. $n=8$. All teachers were women.

Teachers’ Family Involvement Practices Survey (Garcia, 2004). This questionnaire measured levels of family involvement practices as reported by teachers. It addressed 24 practices covering the six categories in Epstein's (2001) typology of familyschool-community involvement with 24 items. Type 1 questions measured the number of times, 0 to 6 or more, that the teacher focused on assisting parents with parenting issues since the beginning of the year. Type 2 questions measured the estimated percentage of parents contacted during the last academic year. Type 3 questions measured the number 
of times, 0 to 6 or more, that practices to promote volunteers were used. Type 4 items measured the number of times, 0 to 6 or more, that the teacher used certain activities to assist families in home learning during a month long period. Type 5 questions explored the percentage of time that teachers promoted parent decision-making roles. Type 6 estimated the frequency, 0 to 6 times or more, that the teacher collaborated with the community since the school year started. A copy of this instrument is provided in Appendix B.

Teachers' parent involvement practices in both groups tended to be Types 2, 3, and 4 . Type 5 was practiced by only one teacher in the experimental group and at only the lowest percentage level (5\%). Only three teachers overall practiced Type 1 or Type 6 activities. Both groups of teachers practiced Type 2 activities a similar percentage of times. The control group yielded 54\% and 59\% for the experimental group teachers. Results for both groups on the Teacher's Family Involvement Practices Survey (Garcia, 2004) are displayed in Table 5.

Family Involvement Teacher Efficacy Scale. Developed by (Garcia, 2004) this scale consisted of 35 Likert-type items measuring teachers' perceived levels of efficacy in relation to specific types of family involvement practices. The six-point scale ranged from 1 (strongly agree) to 6 (strongly disagree). Sample items in this scale are "Teachers possess the skills to design learning activities for students to complete with parental assistance"; "I don't have the necessary skills to offer training that may enable parents to serve as representatives in decision-making bodies"; and "When my students are showing 
Table 5

Results of the Parent Involvement Practices Survey

\begin{tabular}{|c|c|c|c|c|c|c|}
\hline \multirow[b]{2}{*}{ Teacher } & \multicolumn{6}{|c|}{ Types from Epstein’s (2001) Typology } \\
\hline & Type 1 & Type 2 & Type 3 & Type 4 & Type 5 & Type 6 \\
\hline \multicolumn{7}{|c|}{ Experimental Group } \\
\hline Teacher 1 & 0 & $66 \%$ & $1-2$ & $3-6$ & $0 \%$ & 0 \\
\hline Teacher 2 & $1-2$ & $62 \%$ & $9-12$ & $9-12$ & $0 \%$ & $2-4$ \\
\hline Teacher 3 & $2-4$ & $47 \%$ & $4-4$ & $2-4$ & $5 \%$ & 0 \\
\hline Teacher 4 & 0 & $64 \%$ & $4-6$ & $3-4$ & $0 \%$ & $1-2$ \\
\hline \multicolumn{7}{|c|}{ Control Group } \\
\hline Teacher 1 & 0 & $52 \%$ & $3-4$ & $5-8$ & $0 \%$ & 0 \\
\hline Teacher 2 & $1-2$ & $26 \%$ & $13-14$ & $18+$ & $0 \%$ & 0 \\
\hline Teacher 3 & 0 & $67 \%$ & $9-12$ & $3-6$ & $0 \%$ & 0 \\
\hline Teacher 4 & 0 & $67 \%$ & $9-12$ & $9-12$ & $0 \%$ & $1-2$ \\
\hline
\end{tabular}

progress, it is usually because I have been able to effectively engage their parents in providing additional support at home." The instrument yielded a possible score ranging from 35 to 210 points. The level of teacher efficacy in parent involvement was determined by scores on the total scale. Scores less than 70 indicate a low level of efficacy in parental involvement, 71-140 indicated medium efficacy in parental involvement, and 141 to 210 is considered the high range of efficacy in parental involvement. The scores for the experimental group teachers were 138, 142, 152 and $164(M=149)$, while the control group teachers' scores were $140,143,158$, and $163(M=152)$. The alpha 
interitem correlation coefficient for this instrument was .85. A copy of this instrument is provided in Appendix C.

\section{Procedures}

The Teacher's Family Involvement Practices Survey (Garcia, 2004) and the Family Involvement Teacher Efficacy Scale (Garcia, 2004) were distributed to participating teachers at the start of the school year in 2007 and returned to the researcher for analysis. The survey provided demographic information as well as data on the teachers' parent involvement practices. Parent questionnaires were completed on a pre and post basis and yielded responses on demographic variables. Parental efficacy levels were measured by the Parent Perceptions of Parent Efficacy Scale (Hoover-Dempsey et al., 1992) and survey questions concerning the level and type of involvement in home learning, using the researcher developed H.E.L.P. Parent Involvement in Home-learning Scale. Parents received the questionnaires as part of an orientation program prior to the intervention. Parents who could not attend the orientation, received the questionnaires via their children, and returned them to their child's classroom teacher.

Prior to the beginning of the project, all experimental group parents were given an orientation packet that provided instructions on the use of the home-learning activities. A sample can be found in Appendix D. The packet also contained the parent questionnaires and contact numbers and e-mail as a means of addressing any questions that surfaced among the parents. Control parents received only the questionnaire and a letter with instructions for completion of the questionnaire. A presentation was made to parents attending at the school curriculum night. The presentation included an introduction to the 
study's goals and an opportunity to examine sample materials and ask questions about the program.

In this school setting, home-learning in reading consisted of nightly spelling practice and two reading worksheets assigned weekly. The classroom teachers assigned worksheets in reading that dealt with vocabulary and phonics practice in areas and skills that the students had mastered in class. Parental involvement was not usually expected or required for the completion of this homework. One of the intervention's goals was to provide more opportunities for parental involvement in home-learning activities rather than simple homework assignments. The experimental group participated in Project H.E.L.P., while the control group followed the usual school procedure.

The intervention consisted of 12 weeks of interactive home-learning assignments that required parents/caregivers to work directly with the child to complete the activities. These twelve units provided instructions to parents/caregivers on the steps necessary to use specific reading strategies to teach comprehension skills. The skills covered every week included: previewing and predicting, vocabulary identification and meaning, comprehension of story details, decoding and fluency, writing from a prompt. These skills were repeated in each of the 12 packets. A list of books and corresponding skills can be found in Figure 1.

Each Friday, for 12 weeks from October 2007 until February 2008, the students in both experimental classes took home a work packet that contained a storybook and five detailed assignments with complete instructions for parental interaction. A sample parentchild assignment and instructional guidelines are provided in Figure 2. 
The parents were instructed to complete the assignments at a time and place comfortable for their family situation. Assignments were due the following Friday, but could be returned anytime during the week. Late assignments were also accepted to provide flexibility. A sample packet for one of the weekly units can be found in Appendix E.

\begin{tabular}{clll}
\hline Week & \multicolumn{1}{c}{ Title of Book } & \multicolumn{1}{c}{ Reading Skill Addressed } & \multicolumn{1}{c}{ Extension } \\
\hline 1 & I Need an Eraser & Connecting prior knowledge & Graphing \\
\hline 2 & The Sky is Falling & Connecting prior knowledge & Classifying \\
\hline 3 & Community Helpers & Connecting prior knowledge & Sentences \\
\hline 4 & The Busy Pond & Classifying & Classifying \\
\hline 5 & What's for Dinner & Problem/solution & Inferencing \\
\hline 6 & All Kinds of Farms & Predicting & Classifying \\
\hline 7 & Maddy Loves to March & Sequencing & Sentences \\
\hline 8 & What is in the Box & Inferencing & Narrative writing \\
\hline 9 & Where is Cub? & Sequencing events & Story writing \\
\hline 10 & The Food Chain & Sequencing events & Classifying \\
\hline 11 & Gaggle, Herd, or Murder & Recording on a chart & Sentences \\
\hline 12 & The Snowstorm & Sequencing events & Narrative writing \\
\hline
\end{tabular}

Figure 1. Reading books, corresponding skills addressed, and extention activities.

The home-learning packets were written by the researcher using materials provided by Readinga-z.com (2007), an online service that provides both leveled decodable stories and suggested instructional support materials. The packets were designed using a variety of instructional support materials which were reorganized to fit the goals of the intervention. Stories were selected at three different instructional reading levels to complement student reading progress in the classroom.

Each day the parent was guided through the process with the child. On Day 1, the story was introduced and the title page and author discussed. At this time, the parent and child also discussed the author's purpose in writing the story. Day 2 provided an 
introduction to the story vocabulary. Day 3 introduced a comprehension strategy and provided questions for the parents to ask their children. On Day 4, the student decoded and read the story with the parent and an interesting extension activity was suggested. Day 5 required the child to write something based on a prompt related to the story.

\section{Days of Reading Homework}

\section{Dear Parenis,}

In The Busy Pond, a boy sees many animals and plants when he goes to the pond. He notices what each animal is doing and what the plants look like. Repetitive text, high-frequency words, and supportive pictures make this book perfect for emerging readers.

\section{Weekly Book: The Busy Pond \\ By: Kate Page}

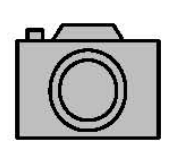

\section{Day 1: Preview/Picture Walk}

- Ask your child the following questions before reading:

Ask your child to tell you what they know about a pond. Explain that a pond is a small body of water that is surrounded on all sides by land.

Ask your child what types of animals and plants they would expect to see in or around a pond.

- Show your child the front and back covers of the book and read the tirle with them. Ask why they might read a book called the Busy Pond.

- Show your child the tirle page. Discuss the information on the page. Share the Title and Author's name.

- Ask your child to name the animals that they see in the pictures.

Figure 2. Sample parent-child assignment and instructional guidelines. 
Parents indicated on the materials that each section had been completed. All materials were returned to the teacher except the books, which the children were encouraged to keep and read again at home. This provided reading materials for the parents to continue sharing with their child. Records were kept of the number of packets completed by each child.

Post intervention questionnaires were distributed the last week of the homelearning intervention. Parents were contacted until all questionnaires were returned. Student test results on the Brigance Diagnostic Comprehensive Inventory of Basic Skills, Revised (Glascoe, 1999) were obtained by a trained testing team individually testing and documenting results for both the pre and post tests. Raw scores were converted to grade level equivalents using tables from the CIBS-R Standardization and Validation Manual (Glascoe). Raw scores and grade level equivalents were recommended by the test developer for pre and post test comparisons.

\section{Implications}

This study utilized the following instrument with the parents/caregivers and their children. Teacher data were collected with the Family Involvement Teacher Efficacy Scale (Garcia, 2004) and the Teacher's Family Involvement Practices Survey (Garcia, 2004), in order to establish equivalence among teachers regarding their levels of efficacy regarding parental involvement, and practices utilized in their classrooms. Parents completed a pre/post survey consisting of Part I of the H.E.L.P. Parent Involvement Home-Learning Scale and Part II of the Parent Perceptions of Parent Efficacy Scale (Hoover-Dempsey et al., 1992). This parent questionnaire provided data to answer the first two research questions concerning the levels of parent/caregiver involvement in 
home-learning, and the levels of parental/caregiver perceived self efficacy. The children's data were gathered pre and post with the Brigance CIB-S reading comprehension subtest in order measure the impact of the intervention on reading comprehension and to answer the third research question.

Parent Demographic Information

The cover sheet for each parent questionnaire contained a data sheet for gathering demographic information. Data collected during the intervention period on the parent questionnaires distributed at the orientation session or sent home to the parents included: parent's name, child's name, family phone number, and language most often spoken in the home. Respondents were asked to provide their last level of education completed. Choices included elementary school, some high school, high school graduate or GED, some college, or college degree. Parents were also asked to select a family income level of $0-\$ 20,000, \$ 20,000-\$ 40,000, \$ 40,000-\$ 60,000, \$ 60,000-\$ 80,000$ or $\$ 80,000$ and above.

\section{Measure of Parental Efficacy}

Changes in levels of parental efficacy were measured with the Parent Perceptions of Parent Efficacy Scale (Hoover-Dempsey et al., 1992) administered on a pre/post basis. Permission to use or modify this scale was granted by Kathleen Hoover-Dempsey and Howard Sandler on the Family-School Partnership Lab (2008) webpage. This scale contains 12 Likert-type items that focus on the parents' perception of their ability to influence children's learning. The authors developed this scale during a study of relationships among teacher efficacy, parent efficacy, and parent involvement in elementary schools (Hoover-Dempsey et al., 1992). The scale was based on research on 
personal efficacy and teacher self-efficacy (Ashton, Webb, \& Doda 1983; Bandura, 1977, 1984, 1986; Dembo \& Gibson, 1985) and the authors support the scale's validity based on its grounding in this literature. The authors reported an alpha reliability of .81 .

Items in the Parent Perceptions of Parent Efficacy Scale (Hoover-Dempsey et al., 1992) focused on assessment of parents' general abilities to influence children's school outcomes and specific effectiveness in influencing children's school learning. Items were scored on a 5-point scale ranging from 1 (strongly disagree) to 5 (strongly agree). Negatively worded items were rescored so that higher scores uniformly reflected higher efficacy. The scale includes items such as "I know how to help my child do well in school" and "If I try hard, I can get through to my child even when he or she has trouble understanding something." A sample can be found in Appendix D.

\section{H.E.L.P. Parent Involvement Home-Learning Scale}

The parent/caregiver questionnaire included 10 questions designed by the researcher based on literature that identifies similar types of items that address practices in home-learning (Hoover-Dempsey et al., 2001). The items included in this survey are displayed in Figure 3. The parents/caregivers completed these questions on a pre/post basis. Parents/caregivers self reported the amounts of participation on a 4 or 5 point scale (8 questions had a 4 point scale, and 2 questions had a 5 point scale) that indicated the frequency or amount of time spent in home-learning parent participation. The results from the pre and post questionnaires were analyzed to determine changes in the degrees of parental/caregiver participation over the intervention period.

The survey was field tested prior to the intervention. On conference night (2006), parent participants agreed to respond to a sample questionnaire on parent involvement in 
home-learning and provide feedback on the questionnaire. Thirty-five parents took the 12-question H.E.L.P. Parent Involvement Home-Learning Scale. The parents/caregivers answered questions concerning the survey experience. This procedure was used to

\section{1) I provide a space and materials to complete homework assignments.} $1=$ always, $2=$ sometimes, $3=$ seldom, $4=$ never

2) I complete homework during a regular time set for homework. $1=$ never, $2=1-2$ times a week, $3=3-4$ times a week, $4=5$ times a week

3) I communicate with the teacher concerning homework (phone, agenda, notes, email). $1=$ never, $2=1-2$ times a week, $3=3-4$ times a week, $4=5-6$ times a week, $5=7$ or more

4) I supervise the completion of homework assignments. $1=$ never, $2=1-2$ times a week, 3=3-4 times a week, $4=5$ times a week

5) I correct homework. $1=$ never, $2=1-2$ times a week, $3=3-4$ times a week, $4=5$ times a week

6) I provide rewards for homework completion. $1=$ always, $2=$ sometimes, $3=$ seldom, $4=$ never

7) I spend _ minutes each night on reading homework. $1=$ never, $2=1-10 \mathrm{~min}$., $3=11-20 \mathrm{~min}$., $4=21-30 \mathrm{~min} ., 5=31$ or more

8) I read with my child as part of weekly homework. $1=$ never, $2=1-2$ times a week, 3=3-4 times a week, $4=5$ times a week

9) I write with my child as part of weekly homework. $1=$ never, $2=1-2$ times a week, 3=3-4 times a week, $4=5$ times a week

10) My child completes homework assignments. $1=$ never, $2=1-2$ times a week, 3=3-4 times a week, $4=5$ times a week

Figure 3. Items from the H.E.L.P. Parent Involvement Home-learning Scale

determine if the questions and instructions were clear (Fowler, 2008). The following questions were included in the field test: (a) Were the instructions clear? (b) Did you have any problems understanding any question? (c) Did you have a problem answering any question? and, Please add any comments or suggestions for improvement. The results 
of this field test are displayed in Table 6. One parent had a problem with understanding two questions and answering one. Two other parents had a problem understanding one question. Only two parents commented on the survey. One thought it was too long and the other suggested it was too crowded. It was decided that the instrument performed well and did not need revisions.

Table 6

Results of the Field Test Survey Questions

Number of Responses

Survey Item

1) Were the instruments clear?

2) Did you have any problem understanding any question?

3) Did you have any problem answering any question?

Yes

34

3

34
No

1

35

32

35

35

\section{Measure of Reading Comprehension}

Changes in student reading achievement were assessed using the Brigance Diagnostic Comprehensive Inventory of Basic Skills, Revised (Glascoe, 1999), reading comprehension subtest administered on a pre/post basis on available alternative forms. The test author claims that the test has a high degree of inter-rater and test-retest reliability (.95), excellent alternative forms reliability (.96), and outstanding internal consistency as measured by the Guttman Lambda Coefficient ( $\lambda=.99$ for 6 year olds and $\lambda=.90$ for 7 year olds). The test validity correlates favorably with other norm referenced 
tests such as the Iowa Tests of Basic Skills, the Stanford Achievement Test, and the California Achievement Test. The correlation between the CIB-S and these criterion measures was .72 in the reading comprehension composite (Glascoe, 1999). Test reviewers state that the test has been shown to be an effective measure of both general cognitive ability and discrete mastery and that the high test-retest correlations for the reading comprehension subtest provide a high degree of consistency in repeated testing (Cizek \& McLellan, 2004). This test is approved for use by the local school authority.

The reading comprehension subtest was administered individually to all students the week before conducting the intervention. All students were tested beginning at the primer level because the test authors suggested that level for new first graders. Student tests were scored using the following scale: primer $=0.5$, lower first grade $=1.0$, upper first grade $=1.5$, lower second grade $=2.0$, upper second grade $=2.5$, lower third grade $=3.0$, upper third grade $=3.5$, and fourth grade $=4.0$. For primer, lower first grade, and upper first grade levels, the assessment was made by asking the students to read a story silently, listen to questions read aloud, and tell the best answer to each question. The reading comprehension assessments for lower second-grade to sixth-grade level required the student to read the selection, and to read and respond to each of five multiple choice questions. The students were allowed to attempt the test up to the highest grade level at which they could answer four out of five questions correctly. The post test was administered, on an alternative form, after the final week of the intervention. Assessors kept logs of each response and alternative forms were used to provide pre and post tests. The assessment provided raw scores for each individual child. Grade 
equivalent scores were produced from the raw scores using tables provided in the Standardization and Validation Manual of the CIBS-R.

\section{Data Analysis}

Descriptive statistics were used to analyze the demographic variables. These included frequencies, percentages, means, and standard deviations. Demographic data were compared between groups using chi-square and $t$-tests. Data collected from the parents (control and experimental) on a pre/post basis on the Parent Perceptions of Parent Efficacy Scale (Hoover-Dempsey et al., 1992) were analyzed using paired samples $t$-tests and independent samples $t$-tests to determine changes in self-efficacy related to their perception of their ability to help their children with home-learning. Additionally, data from the 10 question H.E.L.P. Parent Involvement Home-Learning Scale were compared using Wilcoxon signed rank tests and Wilcoxon rank sum tests to determine differences in degree and type of involvement. Students' test results on the Brigance reading comprehension subtest, administered on a pre/post basis, were subjected to a paired sample $t$-test to determine differences in levels of reading comprehension within each group. Mean differences between the two groups were compared using independent samples $t$-tests to determine if any significant differences in self-perceived efficacy or reading comprehension scores existed between the groups after the intervention.

\section{Summary}

The instruments utilized for the collection of data for this study were: the Family Involvement Teacher Efficacy Scale (2004) and the Teacher's Family Involvement Practices Survey (Garcia, 2004) used for establishing equivalency of parental teacher 
efficacy and parental involvement practices across teachers; a parent/caregiver survey that contained two parts, the H.E.L.P. Parent Involvement Home-Learning Scale and the Parent Perceptions of Parent Efficacy Scale (Hoover-Dempsey et al., 1992), which provided data for answering the first two research questions concerning the levels of parent/caregiver involvement in home-learning and the levels of parental/caregiver perceived self efficacy; and the Brigance CIB-S reading comprehension subtest to reflect the impact of the intervention on the reading comprehension of students and answer the third research question. The instruments used to answer the research questions and the corresponding analyses are displayed in Table 7.

Table 7

Study Instruments

\begin{tabular}{ll}
\hline \multicolumn{1}{c}{ Research Question } & \multicolumn{1}{c}{ Instrument } \\
\hline 1. $\begin{array}{l}\text { Does participation in the home education- } \\
\text { learning program (H.E.L.P.) increase perceived } \\
\text { levels of parental efficacy among }\end{array}$ & $\begin{array}{l}\text { Parent Perceptions of Parent } \\
\text { Efficacy Scale (Hoover- } \\
\text { Dempsey et al., 1992) }\end{array}$ \\
parents/caregivers who participate as compared & \\
to those who do not participate? & \\
2. Does participation in H.E.L.P. increase the levels & H.E.L.P. Parent Involvement \\
of home learning involvement practices among & Home-Learning Scale \\
parents/caregivers who participate as compared & \\
to those who do not participate? & \\
3. Are there differences in scores in reading & Brigance Diagnostic \\
comprehension among children whose & $\begin{array}{l}\text { Comprehensive Inventory of } \\
\text { parents/caregivers participate in H.E.L.P. as }\end{array}$ \\
compared to those who do not participate? & $\begin{array}{l}\text { [reading comprehension } \\
\text { subtest] }\end{array}$
\end{tabular}

Note. $t$-tests were used to analyze collected data for question 1 and 3. Question 2 was analyzed by Wilcoxon signed ranks test and Wilcoxon rank sum test. 
Chapter 3 provided a description of the research design used in this study. It presented the setting and participants, the procedures, and the intervention. This chapter also provided a description of the instruments used to collect participants' data and the corresponding data analysis. 


\section{CHAPTER IV}

\section{RESULTS}

This study investigated a parent involvement intervention to determine if it generated differences in levels or parental/caregiver self efficacy and exhibited practices in home-learning between control/experimental groups, and the impact of this involvement on the academic achievement of students in reading comprehension. This chapter is organized in terms of the three specific research questions posed in chapter 1. The first question asked if participation in the home-learning program (H.E.L.P.) increased the perceived levels of parental efficacy among parents who participated as compared with those who did not. The second question asked if participation in H.E.L.P. would increase the levels of home-learning involvement practices among parents/caregivers who participate as compared to those who did not participate. The third research question asked if there were differences in scores in reading comprehension among children whose parents/caregivers participate in H.E.L.P. as compared to those who do not participate.

\section{Participants' Demographics}

A total of 146 students and their parents/caregivers, representing a convenience sample of eight first-grade classes, participated in the study. Four classes $(n=74)$ were selected as an experimental group and the remaining four classes $(n=72)$ served as the control group. All students' parents/caregivers were asked to complete a parent questionnaire before and after the intervention. The initial questionnaire contained demographic questions that concerned the parents'/caregivers' level of education, family 
language, and family income level. The demographic data collected on this questionnaire are displayed in Table 8 .

The majority of both groups, experimental $96.0 \%$ and control $97.2 \%$, reported that English was the primary language spoken in the home. While the parents' other characteristics seemed fairly similar for each group, statistical analysis using chi-square confirmed the equivalence of the experimental and control groups. For the items mother's education and father's education, the first two categories, elementary school and some high school, were combined to provide the required numbers for a chi-square analysis. The chi-square results for mother's education, $\chi^{2}(3, N=144)=1.59, p=.662$ indicates that there was no significant difference between the groups. The chi-square results, $\chi^{2}(3$, $N=133)=2.07, p=.558$, for father's education also indicates no significant differences between the groups. On the family income item, $\chi^{2}(4, N=133)=7.75, p=.101$, there was no significant relationship between income and group. These results indicate that the experimental group and control group parents/caregivers were both similar on the demographic results.

\section{H.E.L.P. Participation}

Project H.E.L.P. consisted of 12 interactive home-learning packets that were completed by the students with the assistance of a parent/caregiver. In total, 73 students (one student withdrew in the second week of the intervention) completed a mean of 10.6 packets over the 12-week period of the intervention. Frequencies and percentages of the packets completed by the students participating in the study are displayed in Table 9 . Results show that $89.3 \%$ of participants completed 9 or more packets during the 12 -week intervention period. 
Table 8

Frequencies and Percentages of Demographic Data from the Parent Questionnaires for the Experimental Group and the Control Group

\begin{tabular}{|c|c|c|c|c|}
\hline \multirow[t]{2}{*}{ Demographic } & \multicolumn{2}{|c|}{ Experimental Group $(n=74)$} & \multicolumn{2}{|c|}{ Control Group $(n=72)$} \\
\hline & No. & $\%$ & No. & $\%$ \\
\hline \multicolumn{5}{|c|}{ Mother's Education } \\
\hline Elementary & 2 & 2.7 & 0 & 0.0 \\
\hline $\begin{array}{l}\text { Some High } \\
\text { School }\end{array}$ & 9 & 12.2 & 8 & 11.1 \\
\hline HS Grad/GED & 20 & 27.0 & 25 & 34.7 \\
\hline Some College & 22 & 29.7 & 24 & 33.3 \\
\hline College Degree & 19 & 25.7 & 15 & 20.8 \\
\hline (Missing) & 2 & 2.7 & 0 & 0.0 \\
\hline \multicolumn{5}{|l|}{ Father's Education } \\
\hline Elementary & 4 & 5.4 & 1 & 1.4 \\
\hline $\begin{array}{l}\text { Some High } \\
\text { School }\end{array}$ & 6 & 8.1 & 12 & 16.7 \\
\hline HS Grad/GED & 28 & 37.8 & 29 & 40.3 \\
\hline Some College & 15 & 20.3 & 16 & 22.2 \\
\hline College Degree & 14 & 18.9 & 8 & 11.1 \\
\hline (Missing) & 7 & 9.5 & 6 & 8.3 \\
\hline \multicolumn{5}{|l|}{ Family Language } \\
\hline Creole & 1 & 1.4 & 1 & 1.4 \\
\hline English & 71 & 96.0 & 70 & 97.2 \\
\hline Igboo & 1 & 1.4 & 0 & 0.0 \\
\hline Spanish & 1 & 1.4 & 1 & 1.4 \\
\hline \multicolumn{5}{|l|}{ Family Income } \\
\hline$\$ 20 \mathrm{k}$ or less & 16 & 21.6 & 19 & 26.4 \\
\hline$\$ 20 \mathrm{k}-\$ 40 \mathrm{k}$ & 20 & 27.0 & 25 & 34.7 \\
\hline$\$ 40 \mathrm{k}-\$ 60 \mathrm{k}$ & 20 & 27.0 & 10 & 13.9 \\
\hline$\$ 60 \mathrm{k}-\$ 80 \mathrm{k}$ & 8 & 10.8 & 4 & 5.6 \\
\hline$\$ 80 \mathrm{k}$ or more & 3 & 4.1 & 8 & 11.1 \\
\hline (Missing) & 7 & 9.5 & 6 & 8.3 \\
\hline
\end{tabular}


Table 9

Frequencies and Percentages of Packets Completed by Participants in H.E.L.P.

\begin{tabular}{cccc}
\hline $\begin{array}{c}\text { No. of } \\
\text { Packets }\end{array}$ & Frequency & $\%$ & Cumulative $\%$ \\
\hline 0 & 1 & 1.4 & 1.4 \\
2 & 1 & 1.4 & 2.7 \\
4 & 1 & 1.4 & 4.1 \\
6 & 2 & 2.7 & 6.8 \\
7 & 2 & 2.7 & 9.6 \\
9 & 3 & 4.1 & 13.7 \\
10 & 13 & 17.6 & 31.5 \\
11 & 15 & 20.3 & 52.1 \\
12 & 35 & 47.3 & 100.0
\end{tabular}

Note. $n=73$ one student withdrew from the starting sample $n=74$.

Results for the Research Questions

Research Question 1. Does participation in the home-learning program (H.E.L.P.) increase perceived levels of parental efficacy among parents who participate as compared to those who do not participate?

A total of 145 parents responded to the pre-intervention questionnaires that were distributed. Only questionnaires that had at least ten of 12 questions answered, experimental $(n=72)$ and control $(n=70)$, were used for analysis. These questionnaires contained 12 items that were developed by Hoover-Dempsey et al. (1992) under a previous instrument entitled Parent Perceptions of Parent Efficacy Scale. The items 
concerned parents' perceived self efficacy in relation to their children's school work. All items used a Likert-type scale ranging from 5 (strongly agree) to 1 (strongly disagree). Items $12,13,16,17,18,21$ were worded negatively and the scores were reversed so that a higher score would indicate higher efficacy. Possible total scores for the scale ranged from 12 to 60 .

Data from the pre-questionnaire was compared by independent samples $t$-test. Results indicated that there was no significant difference in the perceived levels of parent/caregiver efficacy between the experimental group $(M=40.42, S D=6.65)$ and the control group $(M=41.29, S D=6.59), t(141)=.79, p=.431$. These scores show that the groups had similar levels of efficacy when the intervention began. Results of this comparison are displayed in Table 10.

After the intervention, the parents/caregivers from the experimental group returned 72 post questionnaires and the control group returned 70 questionnaires. Paired sample $t$ tests were used to compare the data within each group. Post test results indicated that both experimental group parents $(M=50.26, S D=5.30), t(71)=15.04, p<.001$, and control group parents $(M=44.05, S D=6.57), t(69)=5.90, p<.001$ had significantly improved from pre to post. The results of this analysis are displayed in Table 10 .

The mean increases from pre to post were compared by an independent samples $t$ test to determine if there was a difference between the two groups' scores after the intervention. These results indicated that there was a significant difference between the groups in parental efficacy from the pre to post, $t(140)=8.79, p<.001$, with the experimental group's mean efficacy increasing 9.85 points $(S D=5.56)$ compared to only $2.75(S D=3.90)$ for the control group. Results indicated that both groups of 
parents/caregivers grew in perceived efficacy over the intervention period. However, results comparing the mean differences for both groups indicate that the improvement for the experimental group was significantly higher than for the control group. This comparison is displayed in Table 11.

Table 10

Comparison of the Pre and Post Test Means on the Parent Perceptions of Parent Efficacy Scale by Group

\begin{tabular}{lcccc}
\hline \multicolumn{1}{c}{ Group } & $M$ & $S D$ & $t$ & $p$ \\
\hline $\begin{array}{l}\text { Experimental }(n= \\
\text { 72) }\end{array}$ & & & 15.04 & $<.001^{* * *}$ \\
$\quad$ Pre & 40.42 & 6.65 & & \\
$\quad$ Post & 50.26 & 5.30 & & \\
Control (n=70) & & & 5.09 & $<.001^{* * *}$ \\
$\quad$ Pre & 41.29 & 6.59 & & \\
Post & 44.05 & 6.57 & & \\
$* * * \mathrm{p}<.001$ & & & &
\end{tabular}

Note. Possible total scores for the scale ranged from 12 to 60 .

Table 11

Comparison of the Experimental Group and Control Group Mean Increases from Pre to Post on the Parent Perceptions of Parent Efficacy Scale

\begin{tabular}{lcccc}
\hline \multicolumn{1}{c}{ Group } & $M$ & $S D$ & $t$ & $p$ \\
\hline & & & & \\
Experimental $(n=$ & 9.85 & 5.56 & & $<.001^{* * *}$ \\
$\begin{array}{l}72) \\
\text { Control }(n=70)\end{array}$ & 2.75 & 3.90 & & \\
\hline$* * * \mathrm{p}<.001$ & & & & \\
\end{tabular}


In addition to analyzing the scores obtained from the total questionnaire, the study analyzed data pertaining to each individual item to determine which items provided the differences between groups. These results indicate that experimental parents/caregivers showed a significant increase over the intervention period in items 11 , $12,13,14,15,18,20$, and 22 . The items were (11) I know how to help my child do well in school, (12) My child is so complex I never know if I'm getting through to him or her, (13) I don't know how to help my child make good grades, (14) A students' motivation to do well in school depends on the parents, (15) I feel successful about my efforts to help my child learn, 18) I don't know how to help my child learn, (20) I make a significant difference in my child's performance, (22) My efforts to help my child learn are successful. The control group parents/caregivers also had significant increases on questions $12,13,18$, and 22.

An independent sample $t$-test was utilized to determine if there were any differences between the groups on the individual items after the intervention. Results indicated that the experimental group had significantly greater increases on items 11,13 , $14,15,18,20$, and 22 . There were no significant differences between the groups on items (12) My child is so complex I never know if I'm getting through to him or her, (16) Other children have more influence on my child's grades than I do, (17) Most of a student's success in school depends on the classroom teacher, so I have only limited influence, (19) If I try hard, I can get through to my child even when he or she has difficulty understanding something, and (21) Other children have more influence on my child's motivation to do well in school than I do. Results for the individual items are displayed in Table 12. 
Table 12

Comparison of the Experimental Group and Control Group Mean Differences from Pre to Post on the Parent Perceptions of Parent Efficacy Scale

\begin{tabular}{|c|c|c|c|c|c|}
\hline \multirow[b]{2}{*}{ Item } & \multicolumn{2}{|c|}{$\frac{\text { Experimental }}{\text { Group }(n=72}$} & \multicolumn{2}{|c|}{$\frac{\text { Control Group }}{(n=68)}$} & \multirow[b]{2}{*}{$\mathrm{p}$} \\
\hline & $\mathrm{M}$ & SD & $\mathrm{M}$ & SD & \\
\hline $\begin{array}{l}\text { (11) I know how to help } \\
\text { my child }\end{array}$ & $1.28 * * *$ & 0.83 & 0.27 & 0.72 & $<.001 * * *$ \\
\hline $\begin{array}{l}\text { (12) I never know if I am } \\
\text { getting through to him/her }\end{array}$ & $1.15 * * *$ & 1.08 & $1.08 * * *$ & 0.81 & .678 \\
\hline $\begin{array}{l}\text { (13) I don't know how to } \\
\text { help my child get good grades }\end{array}$ & $1.08 * * *$ & 1.23 & $0.36 * * *$ & 1.02 & $<.001 * * *$ \\
\hline $\begin{array}{l}\text { (14) A student's motivation } \\
\text { depends on the parents }\end{array}$ & $1.17 * * *$ & 0.98 & 0.13 & 0.88 & $<.001 * * *$ \\
\hline $\begin{array}{l}\text { (15) I feel successful about } \\
\text { my efforts to help my child }\end{array}$ & $1.22 * * *$ & 0.91 & 0.14 & 0.77 & $<.001 * * *$ \\
\hline $\begin{array}{l}\text { (16) Children have more } \\
\text { influence on a child's grades }\end{array}$ & 0.06 & 1.05 & -0.06 & 0.80 & .472 \\
\hline $\begin{array}{l}\text { (17) A student's success } \\
\text { depends on the teacher }\end{array}$ & -0.11 & 1.19 & 0.10 & 0.94 & .241 \\
\hline $\begin{array}{l}\text { (18) I don't know how to } \\
\text { help my child learn }\end{array}$ & $1.08 * * *$ & 0.99 & $0.49 * * *$ & 1.05 & $.001 * *$ \\
\hline $\begin{array}{l}\text { (19) I get through to my } \\
\text { child when he has difficulty }\end{array}$ & 0.22 & 0.98 & -0.19 & 0.94 & .012 \\
\hline $\begin{array}{l}\text { (20) I make a difference in } \\
\text { my child's performance }\end{array}$ & $1.33 * * *$ & 0.75 & 0.13 & 1.00 & $<.001 * * *$ \\
\hline $\begin{array}{l}\text { (21) Children influence my } \\
\text { child's motivation > I do }\end{array}$ & 0.14 & 0.92 & -0.03 & 0.85 & .263 \\
\hline $\begin{array}{l}\text { (22) My efforts to help my } \\
\text { child are successful }\end{array}$ & $1.22 * * *$ & 0.77 & $0.27 * * *$ & 0.78 & $<.001 * * *$ \\
\hline
\end{tabular}

Note. Starred means indicate significant increases from pre to post. Significant $\mathrm{p}$-values indicate differences between group mean increases using a Bonferroni procedure, $\mathrm{p}<.05$. 
Research Question 2. Does participation in H.E.L.P. increase the levels of home learning involvement practices among parents/caregivers who participate as compared to those who do not participate?

A total of 145 parents responded to the pre-intervention questionnaires, H.E.L.P. Parent Involvement in Home-Learning Scale. The questionnaires contained 10 items designed to provide the researcher with information regarding the parents' involvement in home-learning activities with their child. Responses were self reported on a 4 or 5 point scale (eight questions had a 4 point scale, and two questions had a 5 point scale) that indicated the frequency or amount of time spent in home-learning. At the end of the 12-week intervention, parents again provided information on the same 10 questions. Possible total scores for the scale ranged from 10 to 50 with a higher score indicating more parent involvement in home-learning activities.

The questionnaire items pre and post data were analyzed using the Wilcoxon signed ranks test. Results indicated that the two groups were not equivalent on all the questions prior to the intervention. The control group scored higher on questions 1,2,5, and 10 allowing less room for growth in those areas of parent involvement. Pre to post test changes, obtained by the Wilcoxon rank sum test, indicated that the experimental group scores were significantly higher than the control group scores on items 1, 2, 4, 5, 7, 8 , and 10. The control did not increase significantly on any of the questions and decreased significantly on item 8. Results for the individual items on the H.E.L.P. Parent Involvement in Home-Learning Scale are displayed in Table 13.

On item 1, the experimental group started the intervention with $77.8 \%$ and the control group $92.9 \%$ of parents reporting that they always supplied space and materials 
for student homework. The test comparison indicated that there was a significant difference between the pre and post, $p=.001$, but the control group had less room for

Table 13

Pre and Post Test Results for the Experimental Group and Control Group on H.E.L.P. Parent Involvement in Home-Learning Scale

\begin{tabular}{|c|c|c|c|c|c|}
\hline \multirow[b]{2}{*}{ Item } & \multicolumn{2}{|c|}{$\frac{\text { Experimental }}{(n=72)}$} & \multicolumn{2}{|c|}{$\frac{\text { Control }}{(n=70)}$} & \multirow[t]{2}{*}{$p$} \\
\hline & Pre $\%$ & Post $\%$ & Pre $\%$ & Post $\%$ & \\
\hline $\begin{array}{l}\text { (1) I provide a space and } \\
\text { materials (always) }\end{array}$ & 77.8 & 95.8 & 92.9 & 91.4 & $.001 * * *$ \\
\hline $\begin{array}{c}\text { (2) I complete homework } \\
\text { at a regular time ( } 5 \mathrm{X} \text { a week) }\end{array}$ & 3.3 & 65.3 & 55.1 & 55.1 & $<.001 * * *$ \\
\hline $\begin{array}{l}\text { (3) I communicate with the } \\
\text { teacher ( } 3 \text { or more } \mathrm{X} \text { a week) }\end{array}$ & 7.5 & 31.9 & 53.7 & 40.3 & .206 \\
\hline $\begin{array}{l}\text { (4) I supervise completion } \\
\text { of homework ( } 5 \mathrm{X} \text { a week) }\end{array}$ & 5.3 & 75.0 & 11.6 & 26.1 & $<.001 * * *$ \\
\hline $\begin{array}{l}\text { (5) I correct homework ( } 5 \mathrm{X} \\
\text { a week) }\end{array}$ & 4.4 & 66.7 & 68.1 & 53.6 & $<.001 * * *$ \\
\hline $\begin{array}{c}\text { (6) I provide rewards } \\
\text { (sometimes and always) }\end{array}$ & 69.5 & 65.3 & 66.6 & 66.6 & .367 \\
\hline $\begin{array}{l}\text { (7) I spend } \quad \text { minutes on } \\
\text { reading }(21-30 \text { minutes })\end{array}$ & 26.4 & 80.6 & 34.8 & 34.7 & $<.001 * * *$ \\
\hline $\begin{array}{l}\text { (8) I read with my child (3-5 } \\
\text { times a week) }\end{array}$ & 68.1 & 81.6 & 71.4 & 58.5 & $<.001 * * *$ \\
\hline $\begin{array}{l}\text { (9) I write with my child } \\
\text { (3-5 times a week) }\end{array}$ & 56.9 & 59.7 & 58.6 & 51.4 & .387 \\
\hline $\begin{array}{l}\text { (10) My child completes } \\
\text { homework ( } 3-5 \text { X a week) }\end{array}$ & 5.5 & 98.6 & 75.3 & 69.6 & $<.001 * * *$ \\
\hline
\end{tabular}

Note. The $\mathrm{n}$ range is from 139-142. Significant $\mathrm{p}$-values indicate differences between group mean increases using a Bonferroni procedure, $\mathrm{p}<.05$. 
growth on that item from the start. The experimental group increased significantly on several other items including: item (2), completing homework at a regular time, the experimental group increased from $3.3 \%$ at pre to $65 \%$ at post; item (4), supervision of homework completion, the experimental group increased from a pre of 5.3\% to a post of $75 \%$; (5) I correct homework, the experimental increased from pre $4.4 \%$ to post $75 \%$; (7) I spend ___ minutes on reading, experimental increased from pre $26.4 \%$ to post $80.6 \%$; (8) I read with my child, experimental increased from pre $68.1 \%$ to post $81.65 \%$; and (10) My child completes homework, experimental increased from pre 5.5\% to $98.6 \%$. On all of these items the results indicated that the experimental group had a significant increase, $p<.001$, over the control group. Results for items (3) I communicate with the teacher, $p=.206,(6)$ I provide rewards, $p=.367$, and (9) I write with my child, $p=.387$, indicated that there were no significant differences on these items between the experimental and control groups.

Research Question 3. Are there differences in scores in reading comprehension among children whose parents/caregivers participate in H.E.L.P. as compared to those who do not participate?

The children were pre and post tested using the reading comprehension subtest of the Brigance Diagnostic Comprehensive Inventory of Basic Skills (Glascoe, 1999). The technical guidelines for testing recommend use of grade-level equivalents to compare student results on a pre and post. Scores ranged from 0.0 for a non-reader to 7.0 for seventh grade. Prior to the intervention, testing results indicated that both experimental and control students began at similar reading levels. The independent samples $t$-test on 
the pretests indicated no significant difference, $t(141)=0.23, p=.818$, in the reading comprehension grade level equivalent scores between the experimental group $(M=.43$, $S D=.74)$ and the control group $(M=.45, S D=.72)$. These means indicated that both groups began the intervention period at the primer level in reading comprehension. Post test results indicated that both experimental group scores $(M=2.12, S D=.73), t(72)=11.34$, $p<.001$, and control group scores $(M=1.66, S D=.56), t(69)=19.31, p<.001$ had significantly improved from the pre to post test. The experimental group mean indicated the lower second grade reading comprehension level and the control group mean indicated the upper first grade level. The results of the pre and post tests are displayed in Table 14.

Table 14

Comparison of the Pre and Post Test Means on the Brigance Diagnostic Comprehensive Inventory of Basic Skills Reading Comprehension by Group

\begin{tabular}{lcccc}
\hline \multicolumn{1}{c}{ Group } & $M$ & $S D$ & $t$ & $p$ \\
\hline $\begin{array}{l}\text { Experimental } \\
(n=73)\end{array}$ & 0.43 & .74 & 22.34 & $<.001 * * *$ \\
Pre & 2.12 & .73 & & \\
$\quad$ Post & & & & \\
Control $(n=70)$ & 0.45 & .72 & & \\
$\quad$ Pre & 1.66 & .56 & & \\
Post & & &
\end{tabular}

Note. Scale utilized was 0.0 for a non-reader, primer $=0.5$, lower first grade $=1.0$, upper first grade $=1.5$, lower second grade $=2.0$, upper second grade $=2.5$, lower third grade $=3.0$, upper third grade $=3.5$, and fourth grade $=4.0$. 
After the intervention, the experimental group contained 73 students (one had withdrawn) and the control group contained 70 students (two withdrew during the intervention period). The mean increases from pre to post were compared by independent samples $t$-test. These gain scores indicated that the experimental group students scored significantly higher $(M=1.69, S D=.65)$ than the control group students $(M=1.20, S D=.52), t(141)=4.97, p<.001$, on the test of reading comprehension. These results indicated not only that both groups of students increased their scores in reading comprehension over the intervention period, but that the improvement for the experimental group was significantly greater than for the control group. Results of this comparison are displayed in Table 15.

Table 15

Comparison of the Experimental Group and Control Group Mean Increases Pre to Post on the Brigance Diagnostic Comprehensive Inventory of Basic Skills Reading Comprehension

\begin{tabular}{lcccc}
\hline \multicolumn{1}{c}{ Group } & $M$ & $S D$ & $t$ & $p$ \\
\hline & & & 4.97 & $<.001 * * *$ \\
$\begin{array}{l}\text { Experimental }(n= \\
73)\end{array}$ & 1.20 & 0.65 & & \\
Control $(n=70)$ & 1.65 & 0.52 & & \\
$* * * \mathrm{p}<.001$ & & &
\end{tabular}

Note. $M=$ post test minus pre test.

\section{Summary}

This chapter presented the findings pertaining to the three research questions. The results indicated significant differences between the control and experimental groups in the following areas: perceived levels of parental efficacy, parental involvement in home- 
learning activities, and student achievement in reading comprehension. The following chapter discusses the results from this chapter as related to the framework of this study. The conclusions and implications of this study are addressed, and recommendations for future research and practice, particularly as it relates to the field of educational administration, are provided. 


\section{CHAPTER V \\ DISCUSSION}

This chapter presents a discussion of the study. The first section describes the study outlining the purpose, research questions, and methodological design. The second section contains the findings and conclusions of this research. The chapter concludes with a discussion and implications of the findings and recommendations for future research.

\section{Summary of the Study}

This study sought to determine if participation in a home education learning program would impact the perceived levels of parental efficacy among parents/caregivers. Second, the study asked if participation in this program would make any difference in the levels of home-learning involvement practices among parents/caregivers who participate in the completion of home-learning assignments. Third, the study asked if there would be differences in the reading comprehension scores between children whose parents/caregivers participated in an interactive home-learning program and children whose parents/caregivers did not participate.

A total of 146 students and their parents/caregivers representing a convenience sample of eight first grade classes participated in the study. Four classes were selected as an experimental group and the remaining four classes served as the control group. A quasi-experimental research design was used to examine the effects of a home-learning support intervention program on the perceived efficacy levels of the participating parents/caregivers, as measured by the Parent Perceptions of Parent Efficacy Scale (Hoover-Dempsey et al., 1992) administered on a pre/post basis. The amount and type of 
parent involvement in the completion of home assignments was determined by means of a researcher developed instrument, the H.E.L.P. Parent Involvement Home- Learning Scale, also administered on a pre/post basis. Student achievement in reading comprehension was determined by the administration of the Brigance Diagnostic Comprehensive Inventory of Basic Skills (Glascoe, 1999) reading comprehension subtest on a pre/post basis.

The students participated in an interactive home-learning intervention for 12 weeks that required parent/caregiver assistance. The 12 units provided by this intervention each contained 1 week of interactive homework instruction. Each lesson instructed the parents/caregivers on the steps necessary to teach specific reading strategies. Each Friday, for 12 weeks, the students brought home a work packet containing a grade level storybook and five detailed assignments with complete instructions for parental interaction. Included in each packet was a series of five sequential lessons that dealt with vocabulary, picture walk, predicting, comprehension questioning, and a concluding journal prompt. Materials for the program complemented the skills being taught in the classroom. In total, 73 students completed a mean of 10.6 packets over the 12 -week period of the intervention. Results show that $89.3 \%$ of participants completed 9 or more packets during the 12 -week intervention period. The intervention also included an orientation packet that instructed families on the use of the program and included parent assessment questionnaires.

\section{Discussion of the Findings}

The first question in this study addressed whether participation in the home education-learning program makes a difference in the perceived levels of parental 
efficacy among parents/caregivers who participated in the program as compared to those who did not. Data on efficacy were gathered with the Parent Perceptions of Parent Efficacy Scale developed by Hoover-Dempsey et al. (1992). Questions focused on parents' perceptions of efficacy related to children's school learning. Possible total scores for the scale ranged from 12 to 60 .

On the pre-questionnaire, results indicated that there was no significant difference in the perceived levels of parent/caregiver efficacy between the experimental group and the control group, $p=.431$. Results from the pre-intervention questionnaire showed that the experimental $(M=40.42, S D=6.65)$ and control groups $(M=41.29, S D=6.59)$, had similar levels of self-efficacy concerning their children's schooling prior to the intervention. Both the experimental mean of 40.42 and the control mean of 41.29 indicate that the groups fell in the medium range (28-44) of perceived efficacy before the intervention started, indicating that they were moderately self-efficacious.

After the intervention, both groups' mean efficacy scores had significantly improved from the pre. The post control group scores $(M=44.05, S D=6.57)$ indicated that the parents/caregivers in that group fell at the upper range of the medium level of perceived self-efficacy. The experimental group parents'/caregivers' increase in post scores $(M=50.26, S D=5.30)$, on the other hand reflected a significantly greater increase than the control group post scores in their level of perceived self-efficacy over the same period placing the experimental group well into the high range. These results suggest that the experimental parents/caregivers had a significantly more positive perception of their own efficacy than before they participated in the intervention. 
In addition to analyzing the scores obtained from the total questionnaire, individual item scores were analyzed by paired sampled $t$-test to determine differences pre to post for each group. The results of this analysis indicated that the experimental group showed a significant increase on a pre/post basis on items $(11,12,13,14,15,18$, $20,22)$ and the control group scored significantly higher on four items $(12,13,18,22)$. The items were: (11) I know how to help my child do well in school (scored in reverse); (12) My child is so complex I never know if I'm getting through to him or her (scored in reverse); (13) I don't know how to help my child make good grades (scored in reverse); (14) A student's motivation to do well in school depends on the parents; (15) I feel successful about my efforts to help my child learn; (18) I don't know how to help my child learn (scored in reverse); (20) I make a significant difference in my child's performance; (22) My efforts to help my child learn are successful.

Neither group had a significant increase on items (16) Other children have more influence on my child's grades than I do, (17) Most of a student's success in school depends on the classroom teacher, so I have only limited influence, (19) If I try hard, I can get through to my child even when he or she has difficulty understanding something, and (21) Other children have more influence on my child's motivation to do well in school than I do. Also, independent $t$-test results determined that the experimental group had significantly greater increases on items $11,13,14,15,18,20$, and 22 than the control group.

In this study, parents participated in a home-learning program that provided them with direct knowledge and practice of the school curriculum in reading. To complete the assignments, they were required to work through individual skills with their child and by 
doing so they strengthened their self-concepts concerning their own abilities to help their child be successful in school. By increasing the parents' knowledge of the reading process and providing them with the tools to better assist their child with home-learning activities, their perceived self-efficacy was improved.

The results from this study are consistent with the findings of several other studies (Eccles \& Harold, 1996; Grolnick et al., 1997; Hoover-Dempsey et al., 1992; HooverDempsey and Sandler, 1997; Reed et al., 2000) concerning parental efficacy. Findings of the study by Hoover-Dempsey et al. (1992) indicated a positive relationship between parental efficacy and parental involvement behaviors. In a study by Eccles and Harold, the researchers found that efficacy was positively related to school involvement behaviors on the part of parents, and parental involvement was found to be predictive of better academic performance by the students. Parents who believed in their own capacity to influence their child's performance were more involved in school activities. Further, they found that mothers' involvement in their children's reading education was positively related to their confidence in their own abilities. The model developed by HooverDempsey and Sandler (1995) suggests that parental involvement influences children's development and educational outcomes through such mechanisms as modeling, reinforcement, and instruction. The current study focused on parents'/caregivers' use of these techniques to provide positive student outcomes. Other studies with similar results to H.E.L.P. included Grolnick (1997) that made the connection between parental efficacy and parents' active involvement with the school, and Shumow and Lomax (2002) that also provided a link between parental efficacy, parenting behaviors, and student outcomes similar to the constructs examined in this study. The current study differs in 
that it increased parental efficacy by utilizing a home-learning intervention. H.E.L.P. gave parents the materials to help their child work on classroom skills at home. They were designed to make the parent aware of the skills necessary for academic success and to allow the parent to be a successful home tutor. After 12 weeks of assisting their child, the parents' self-perception of their own abilities increased.

The second question addressed in this study asked whether participation in this intervention made any difference in the levels of home-learning involvement practices among parents/caregivers who participated in the completion of home-learning assignments in H.E.L.P. as compared to the group who did not. The scale for the parent involvement questions included 10 items with a Likert-scale that produced scores between 10 and 50. Results indicated that the two groups were not equivalent on all the questions prior to the intervention. The control group scored higher on questions $1,2,5$, and 10 allowing less room for growth in those areas of parent involvement. Post test results indicated that the experimental group increases were significantly higher, $p<.001$, than the control group scores on items 1, 2, 4, 5, 7, 8, 10. These results for the individual items on the H.E.L.P. Parent Involvement in Home-Learning Scale showed that the experimental parent involvement scores increased significantly on items concerning the (1) provision of space and materials to complete homework assignments, (2) providing a regular set time for homework, (4) supervision of the completion of homework assignments, (5) correcting homework, (7) amount of time spent each night on reading homework, (8) reading with the child as a part of weekly homework, (10) and completion of homework assignments. The control group did not increase significantly on any of the 
questions and decreased significantly on item 8, "I read with my child as part of weekly homework".

The results of project H.E.L.P. are consistent with the theories of Bronfenbrenner (1979) and Epstein (1980). Bronfenbrenner proposed that learning is produced by students with the help of schools, parents and community members. Building on Bronfenbrenner, Epstein (1996) created an integrated theory of student learning that included families, schools and communities. Project H.E.L.P. included the parents in the reading instruction of the students and by participating in the H.E.L.P. intervention, the parents/caregivers increased their levels of participation in home-learning, one of the six areas of parent involvement in Epstein's model.

Hoover-Dempsey et al. (1995) examined how homework related to formal learning. One implication of their study was that parents' involvement in homework was based on their understanding of their own abilities. When parents feel confident in their ability to help their child do better, they will spend more time engaged in home-learning activities. The current study used home-learning to increase the amount of parent involvement in home-learning activities and to improve the parents' self-perception of their ability to help their child be successful.

Parents' homework involvement appears to influence student success by supporting student attributes related to achievement. Cooper (2001) data revealed that parent involvement in homework was the strongest predictor of grades. Fishel and Ramirez (2005) reviewed 24 parent involvement programs and provided evidence that the most effective practices were those that included parent tutoring at home and concentrated on one subject, primarily reading or math. Jeynes (2005) results also 
indicate a considerable and consistent relationship between parental involvement and academic achievement. Project H.E.L.P. utilized parents as home tutors, concentrated on reading comprehension, and produced positive achievement gains for the students who participated.

In a 2004 study, Granda conducted a study of two projects that provided home literacy materials to parents to use with their children. One of the programs used home literacy bags with activities to be completed at home by first grade students with their parents. Her results reinforced the idea that home-learning activities can be enjoyable, and beneficial. They can be used to make parents more aware of the types of activities that can be carried out at home to improve student skills, and they can communicate grade level expectations to parents. Project H.E.L.P. also provided this type of parent involvement support, but also concentrated on student achievement. Granda provided only 1 week of home-learning activities and project H.E.L.P. provided five activities a week for 12 weeks and produced measurable significant positive results in achievement.

Another similar study that concerned the effects of interactive homework was conducted by Bailey et al. (2004). That study explored the use of interactive reading homework and parent involvement with children during homework on students' achievement in inferential reading. The Bailey et al. study was similar to the H.E.L.P. intervention because it involved elementary age students, parental involvement in homelearning activities and concerned pre to post improvements in inferential reading. The results indicated that interactive homework increased both parental involvement during reading homework and the students' ability to draw inferences. H.E.L.P. results showed similar increases in parental involvement and student reading comprehension. This study 
concentrated on reading comprehension and was exclusive to first-grade students. H.E.L.P. provided 12 weeks of involvement activities, longer than other studies of interactive home-learning evident in the literature.

The final research question asked if there are differences in the reading comprehension scores between children whose parents/caregivers participated in an interactive home-learning program and children whose parents/caregivers did not participate. All children who participated in the experimental and control groups were pre and post tested in reading comprehension with the Brigance reading comprehension subtest. Scores were reported in grade level equivalents. Prior to the intervention, the experimental group $(M=.43, S D=.74)$ and the control group $(M=.45, S D=.72)$ scores were not significantly different. Because a score of 1.0 indicated a reading level at the beginning of first grade, these means show that both groups began at a mean level below beginning first grade. After the intervention, the experimental group $(M=2.12, S D=.73)$ had a significantly higher reading level after participation in the intervention than did the control group $(M=1.66, S D=.56)$ who did not participate in H.E.L.P. Both groups were actively involved in the process of learning to read and both groups did improve significantly in reading comprehension by the end of the intervention period. The experimental group, however, had a significantly greater increase than did the control.

The results of Project H.E.L.P. support the results of studies that link parent involvement to student achievement. One study with similar results to project H.E.L.P. was by Tizard et al. (1982). In that study researchers found that students who practiced with their parents at home achieved significantly higher scores than those who did not. Also, Henderson (1997) indicated that studies that examined the link between student 
achievement and parental involvement had significantly improved language skills including reading comprehension. Additionally, studies by Yap and Enoki (1994), SuiChu and Willms (1996), and Fantassio et al. (1995) connected parent involvement to increases in student achievement. This is consistent with results from the H.E.L.P. intervention.

Project H.E.L.P. was a home-learning program that relied on parent involvement with the student to increase the student's achievement in reading comprehension. The positive results in this study support the results of others who have examined the relationship between home-learning, parental involvement and student achievement (Jorden et al. 2000; Zellman \& Waterman, 1998).

By concentrating on the comprehension portion of the reading program, the students in the experimental group who participated in the intervention scored significantly higher than the students in the control group on the test for reading comprehension. These results support prior research that linked home-learning to achievement in reading.

Both groups of children, control and experimental, were involved in the process of learning to read during the intervention period. They began below grade level and made good progress in reading as measured by the Brigance sub-test. The significantly higher results, based on the gains achieved, for the experimental group are very encouraging after only a 12 -week intervention. H.E.L.P. provided the experimental group children with five contacts with reading comprehension skills a week and also added a parent/caregiver assisting during the entire process. 


\section{Implications}

This study has provided evidence that interactive home-learning improves levels of parental self-efficacy, increases parental involvement in home-learning activities, and improves student reading comprehension. Based on these findings, providing homelearning activities that encourage interaction between parents and children may help increase the amount of parent involvement and contribute to the improvement of children's performance on a test of reading comprehension. Home-learning intervention packets from H.E.L.P. provided parents with an opportunity to actively participate in specific reading skills lessons with their children regardless of their family circumstances. The intervention helped to minimize the middle-class advantage addressed by several researchers (Christianson \& Sheridan, 2001; Desimone, 1999; Heyman \& Earle, 2000; Kelleghan et al., 1993) by making parent involvement activities available to all the parents whether they worked in the home or workplace. By the very nature of these activities, parents were placed in a position to spend more time with their child on meaningful home-learning activities.

Researchers have reported that parent-child interactions during homework serve to promote educational interest for both the parent and the student (Bailey et al., 2004; Cooper et al., 2001; Epstein, 1995). They further reported that these interactions can positively affect student academic outcomes. The findings from this study corroborated conclusions made by these researchers and added support to the claims that interactive strategies that involve parents in home-learning improve parental involvement and student achievement. 
Results from this study imply that educators should be strongly encouraged to provide parents and children with interactive home-learning assignments. These homelearning assignments will provide the parents with an opportunity to share important literacy acquisition skills with their child. If home-learning materials are provided that complement the current curriculum and provide additional practice for the child in decoding, vocabulary, comprehension questioning, and writing, such as those offered in this intervention, the child may score higher on tests of reading comprehension. To accomplish this, materials must be selected that complement the current skills being taught in the classroom. Storybooks should be selected that are at the children's instructional level, and vocabulary activities designed that use specific vocabulary found in the storybook. Project H.E.L.P. also provided extension activities that touched on other areas of the curriculum including science, social studies, math and art. Journal writing that uses concepts from the story should also be included to provide further assessment of the comprehension skill presented.

\section{Policy Implications}

School administrators are continuously seeking new ways to increase reading scores for the students in their schools through new curricular frameworks/approaches and other interventions. This study has been shown how it can improve student reading comprehension by including the parents in the teaching of reading at home during homelearning time. Since home-learning assignments are often a requirement for teachers, administrators should encourage meaningful homework, similar to H.E.L.P., that has been shown to produce results. 
Current legislation requires that school administrators provide opportunities for parents to participate in the education of their children. H.E.L.P. has been shown to be an effective parent involvement activity. It allows all parents, regardless of family situation, to participate with their child in meaningful activities. By the nature of the assignments, it helps to inform the parents about content in reading instruction and involves them in the school curriculum.

H.E.L.P. is a model that can be used by administrators to help improve the selfefficacy of the parents. Parents who are more efficacious have been shown to participate more freely with the school. They are more likely to help their child with academic issues if they feel they can make a difference. This may impact not only the individual child participating in H.E.L.P., but also the parents' other children who may attend the school. Creating parents as partners in their child's education is a stated goal for many administrators.

\section{Limitations}

This study took place in a rural, southeastern U.S. school district and results should be applied with caution to urban or suburban settings. The students and parents in the study were primarily English-speaking, African American or White, and the results cannot be generalized to other populations. Another limitation was that there were no psychometric measures available for the H.E.L.P. Parent Involvement in Home-Learning Scale.

\section{Recommendations for Further Research}

This study adds to the research literature by providing information regarding the impact of an interactive home-learning program on the self-reported efficacy levels of 
parents/caregivers involved, their level of parent involvement in home-learning, and the reading comprehension scores of students involved in the program. In this section, additional research is recommended to expand knowledge in the areas of efficacy, parent involvement in home- learning, and student achievement.

The results of this study concern only students in one first grade cohort. Research in this area needs to be done with other age groups including other grades in elementary, middle, and high schools. Project H.E.L.P. was implemented in a rapidly growing rural setting that was struggling with changes as it became suburban. Projects of this type need to be in implemented in other settings including urban and suburban. This study produced results in student achievement in just a 12 -week period. Further research can provide structured home-learning to students for longer periods of time, for a full semester, a full year, or several years, to determine if this growth in reading comprehension continues on a longitudinal basis.

Because reading homework is only one part of home-learning, research should be done with other curriculum subjects including math, language arts, science and social studies. This study concerned only one type of home-learning, parent assisted activities, other types of home-learning including student research projects, family discussions of topics, and literature sharing between family members, also need to be explored.

The linkage between parental efficacy and parental involvement should also receive more research. Additional investigations should be conducted that investigate the relationship between the different domains of parental efficacy and various types of parent involvement. Because the goal is improving student academic achievement, and that can be improved through improved parent involvement, new ways to improve the 
quality and amount of parental participation, including increasing parental efficacy, should be studied.

There should also be more studies that provide information on the motivations of parents to participate and assist their child in home-learning. These will aid educators in the task of developing and implementing meaningful home-learning programs for the families they serve. These will provide teachers and administrators with new ways to engage the parents as partners in their child's academic pursuits.

\section{Conclusions}

This study supports the literature that parents'/caregivers' involvement in a school related home-learning initiative can improve their perceived levels of self efficacy. With increased efficacy parents/caregivers felt more confident in their ability to improve student outcomes and increased their levels of involvement in home-learning activities. More parent/caregiver involvement in home-learning activities improved student achievement in the targeted area of reading comprehension. The Home-Education Literacy Program (H.E.L.P.) sought to provide parents/caregivers of first-grade students with detailed instructions in using effective reading comprehension strategies with their children during home-learning activities. The activities increased the parents'/caregivers' abilities and confidence levels to provide instructional assistance to their children in the home, thus increasing the parent's/caregiver's belief that he or she is capable of exerting a positive influence on children's school outcomes. 


\section{REFERENCES}

Addington, D. G. (1996). Effects of parental involvement on mathematics achievement at eighth, tenth, and twelfth grades. Dissertation Abstracts International, 57(11), 4677A. (UMI No. 9710939)

Ardelt, M., \& Eccles, J. (2001). Effects of mothers' parental efficacy beliefs and promotive parenting strategies on inner-city youth. Journal of Family Issues, $22(8), 944$.

Ashton, P., Webb, R., \& Doda, N. (1983). A study of teachers' sense of efficacy [Final report, National Institute of Education]. Gainsville: University of Florida.

Bailey, L. (2006). Interactive homework: A tool for fostering parent-child interactions and improving learning outcomes for at-risk young children. Early Childhood Education Journal, 34(2), 155-167.

Bailey, L., Silvern, S., Brabham, E., \& Ross, M. (2004). The effects of interactive reading homework and parent involvement on children's inference response. Early Childhood Education Journal, 32(3), 173-178.

Baker, A., \& Sodon, L. (1997). Parent involvement in children's education: A critical assessment of the knowledge base. New York: NCJW Center for the Child.

Baker, A. J., \& Sodon, L. M. (1998). The challenges of parent involvement research. ERIC Clearinghouse on Urban Education, 132. (ERIC Document Reproduction Service No. EDA429030)

Baker, D. P., \& Stevenson, D. L. (1986). Mothers' strategies for children's school achievement: Managing the transition to high school. Sociology of Education, 59, 156-166.

Bandura, A. (1977). Self-efficacy: Toward a unifying theory of behavioral change. Psychological Review, 84, 191-215.

Bandura, A. (1980). Gauging the relationship between self-efficacy, judgement, and action. Cognitive Therapy and Research, 4(2), 263-268.

Bandura, A. (1984). Recycling misconceptions of perceived self-efficacy. Cognitive Therapy and Research, 8, 231-255.

Bandura, A. (1986). The explanatory and predictive scope of self-efficacy theory. Journal of Social and Clinical Psychology, 4, 359-373.

Bandura, A. (1989). Regulation of cognitive processes through perceived self-efficacy. Developmental Psychology, 25(5), 728-735. 
Berger, E. H. (1981). Parents as partners in education. St. Louis, MO: Mosby Company.

Bourdieu, P., \& Passeron, J. (1977). Reproduction in education, society and culture. Beverly Hills, CA: Sage.

Bowles, S., \& Gintis, H. (1976). The inheritance of inequality. Journal of Economic Perspectives, 16(3), 3-31.

Brody, G., Flor, D., \& Gibson, N. (1999). Linking maternal efficacy beliefs, developmental goals, parenting practices, and child competence in rural single-parent African American families. Child Development, 70(5), 1197-1209.

Bronfenbrennar, U. (1979). Who needs parent education? In H. Jensen (Ed.), Families and communities as educators (pp. 203-223). New York: Teachers College Press.

Christenson, S. L., \& Sheridan, S. M. (2001). Schools and families. New York: Guilford.

Cizek, G., \& McLellan, M. (2004). Review of the BRIGANCE Diagnostic Comprehensive Inventory of Basic Skills, Revised. Mental Measurements Yearbook, 14, 212-215.

Coleman, P., \& Karraker, K. (1998). Self-efficacy and parenting quality: Findings and future applications. Developmental Review, 18(1), 47-85.

Coleman, P., \& Karraker, K. (2000). Parenting self-efficacy among mothers of schoolage children: Conceptualization, measurement, and correlates. Family Relations, 49(1), 13-24.

Connors, L., \& Epstein, J. (2006). Taking stock: Views of teachers, parents, and students on school, family, and community partnerships in high schools (Report No. 25). Baltimore, MD: Johns Hopkins University, Centeron Families, Communities, Schools and Children's Learning.

Cooper, H. (1989). Synthesis of research on homework. Educational Leadership, 47(3), 85-91.

Cooper, H. (2001). The battle over homework. Thousand Oaks, CA: Corwin Press.

Cooper, H., \& Gernsten, R. (2003). Homework tips for parents. Jessup, MD: Education Publications Center.

Cooper, H., Jackson, K., Nye, B., \& Lindsey, J. J. (2001). A model of homework on the performance evalualtions of elementary school students. The Journal of Experimental Education, 69, 181. 
Cooper, H., Robinson, J., \& Patall, E. (2006). Does homework improve academic achievement? A synthesis of research 1987-2003. Review of Educational Research, 76(1), 1-62.

Creswell, J. W. (2003). Research design: Qualitative, quantitative, and mixed methods approaches $\left(2^{\text {nd }}\right.$ ed.). Thousand Oaks, CA: Sage.

Davies, D. (1987). Parent involvement in the public schools. Education and the Urban Society, 19(2), 147-163.

Dembo, M., \& Gibson, S. (1985). Teachers' sense of efficacy: an important factor in school improvement. The Elementary School Journal, 86(2), 173-184.

Desimone, L. M. (1999). Linking parent involvement with student achievement: Do race and income matter? The Journal of Educational Research, 93(1), 11-30.

Easton J. Q., \& Bennett, A. (1990, July). Achievement effects of homework in sixth grade classrooms. Paper presented at the annual meeting of the American Educational Research Association, Boston, MA.

Eccles, J., \& Harold, R. (1996). Parent-school involvement during the early adolescent year. Teachers College Record, 94(3), 968-988.

Education for All Handicapped Children Act of 1975, Public Law 94-142, 20 USC §1400 (1975).

Elementary and Secondary Education Act, Public Law 89-10, 79. Stat. 77, 20 U.S.C. Ch. 70 (1965).

Emory University Strategic Planning. (2004, June). Oxford College Environmental Assessment. Oxford, GA: Author.

Epstein, J. (1980). A longitudinal study of school and family effects on student development. Baltimore, MD: John Hopkins University, Center for Social Organization of Schools.

Epstein, J. (1987a). Parent involvement: What research says to administrators. Education and Urban Society, 19(2), 119-136.

Epstein, J. (1987b). Homework Practices, achievements, and behaviors of elementary school students (CREMS Rep. No. 26). Baltimore, MD: Johns Hopkins University, Baltimore Center for Research on Elementary and Middle Schools.

Epstein, J. (1988). Homework practices, achievements, and behaviors of elementary school students. In J. Epstein (Ed.), School, family, and community partnerships (pp. 236-251). Boulder, CO: Westview Press. 
Epstein, J. (1991). Literacy through family, community, and school interaction. In S. Silvern (Ed.), Advances in reading/language research (pp. 261-276). Greenwich, CT: JAI Press.

Epstein, J. (1992). School and family partnerships. In Encyclopedia of Educational Research (pp. 1139-1151). New York: McMillan.

Epstein, J. (1995). Goals 2000, Title I, and school-to-work legislation: Implications for school, family and community connections. Baltimore, MD: Johns Hopkins University, Center on Families, Communities, Schools and Children's learning.

Epstein, J. (1996). Perspectives and previews on research and policy for school, family, and community partnerships. In A. Booth \& J. Dunn (Eds.), Family-school links: How do they affect educational outcomes? (pp. 209-245). Hillsdale, NJ: Erlbaum.

Epstein, J. (2001). School, family and community partnerships. Boulder, CO: Westview Press.

Epstein, J., Coates, L., Sallinas, K., Sanders, M., \& Simon, B. (1997). School, family, and community partnerships: Your handbook for action. Thousand Oaks, CA: Corwin Press.

Epstein, J. L., \& Sanders, M. G. (2000). Connecting home, school, and community. In M. T. Hallinan (Ed.), Handbook of the sociology of education (pp. 285-306). New York: Kluwer Academic/Plenum.

Epstein, J. L., Sanders, M.G., Simon, B.S., Clark, K., Rodriguez, N., \& Van, F.L. (2002). School, family, community partnerships. Thousand Oaks, CA: Corwin Press.

Family-School Partnership Lab. (2008). Statement of Use. Retrieved June 10, 2008, from http://www.vanderbilt.edu/peabody/family-school/scale-descriptions/usestatement.html

Family and Educational Rights and Privacy Act, 20 U.S.C. $§ 1232 g ; 34$ CFR Part 99 (1974).

Fantussio, J. W., Davis, G. Y., \& Ginsburg, M. D. (1995). Effects of parent involvement in isolation or in combination with peer tutoring on student self concept and mathematics achievement. Journal of Educational Psychology, 87(2), 272-281.

Fishel, M., \& Ramirez, L. (2005). Evidence-based parent involvement interventions with school-aged children. School Psychology Quarterly, 20(4), 371-402.

Fowler, F. J. (2008). Survey research methods. Beverly Hills, CA: Sage. 
Garcia, D. C., (2004). Exploring connections between the construct of teacher efficacy and family involvement practices: Implications for urban teacher preparation. Urban Education, 39(3), 290-315.

Georgia Department of Education. (2007). Report card. Retrieved on June 10, 2008, from http://www.doe.k12.ga.us

Glascoe, F. P. (1999). CIBS-R standardization and validation manual. North Bellerica, MA: Curriculum Associates.

Goals 2000 Educate America Act. (1965). Retrieved May 20, 2008, from http://www.ed.gov/legislation/GOALS2000/The Act/sec401.html

Granda, M. (2004). Increasing parent participation and knowledge using home literacy bags. Intervention in School and Clinic, 40(2), 120-126.

Grolnick, W. S., Benjet, C., Kurowski, C. O., \& Apostoleris, N. H. (1997). Predictors of parent involvement in children's schooling. Journal of Educational Psychology, 89(3), 538-548.

Harter, S. (1978). Effective motivation reconsidered. Toward a developmental model. Human Development, 21(1), 34-64.

Henderson, A. T. (1987). The evidence continues to grow. Columbia, MD: National Committee for Citizens in Education.

Henderson, A. T., \& Berla, N. (Eds.). (1994). A new generation of evidence: The family is critical to student achievement. Columbia, MD: National Committee for Citizens in Education.

Henderson, A. T., \& Mapp, K. L. (2002). A new wave of evidence: The impact of school, family, and community connections on student achievement. Austin, TX: Southwest Educational Development Laboratory.

Heymann, S. J., \& Earle, A. (2000). Low-income parents: How do working conditions affect their opportunity to help school-age children at risk? American Educational Research Journal, 37(4), 833-848.

Hittleman, D. R., \& Simon, A. J. (2002). Interpreting education research: An introduction for consumers of research ( $3^{\text {rd }}$ ed.). Upper Saddle River, NJ: Pearson Education.

Hoover-Dempsey, K., Bassler, O., \& Brissie, J. (1992). Explorations in parent-school relations. Journal of Educational Research, 85(5), 287-294. 
Hoover-Dempsey, K., Bassler, O., Burow, R. (1995). Parents reported involvement in students' homework: Strategies and practices. The Elementary School Journal, 95(5), 435-450.

Hoover-Dempsey, K., Battiato, A., Walker, J., Reed, R., Dejong, J. \& Jones, K. (2001). Parental involvement in homework. Educational Psychologist, 36(3), 195-209.

Hoover-Dempsey, K., \& Sandler, H. (1995). Parental involvement in children's education: Why does it make a difference? Teachers College Record, 97(2), 310332.

Hoover-Dempsey, K., \& Sandler, H. (1997). Why do parents become involved in their children's education? Review of Educational Research, 67(1), 3-42.

Jeynes, W. (2005). A meta-analysis of the relation of parental involvement to urban elementary school student academic achievement. Urban Education, 40(3), 237269.

Jordan, G. E., Snow, C. E., \& Porche, M. B. (2000). Project EASE: The effect of a family literacy project on kindergarten students' early literacy skills. Reading Research Quarterly, 35(4).

Keith, T., Troutman, G., Trivette, P., Keith, P., \& Singh, K. (1993). Does parent involvement affect eighth-grade student achievement? School Psychology Review, 22(3), 474-496.

Kelleghan, T., Sloane, K., \& Alvarez, B. (1993). The home environment and school learning: Promoting parental involvement in the education of children. San Francisco: Jossey-Bass.

Kincheloe, B. (1994). The effect of directed parental involvement in achievement. Dissertation Abstracts International, 55(05), 1214A. (UMI No. 9427403)

Kline, R. B. (2004). Principles and practice of structural equation modeling (2nd ed.). New York: Guilford Press.

Lareau, A. (1987). Social class differences in family school relationships: The importance of cultural capital. Sociology of Education, 60(2), 73-85.

Mattingly, D. J., Prislin, R., McKenzie, T. L., Rodriguez, J. L.\& Kayzar, B. (2002). Evaluating evaluations: The case of parent involvement programs. Review of Educational Research, 72(4), 549-576.

McCarthy, S. (1999). Identifying teacher practices that connect home and school. education and urban society, 32(1), 83-107. 
National Commission on Excellence in Education. (1983). A nation at risk: The imperative for educational reform. Washington, DC: U.S. Government Printing Office.

National Institute for Literacy. (2008). Illiteracy: An incurable disease or education malpractice? Retrieved on June 10, 2008, from http://www.nrrf.org/essay_illiteracy.html

National Right to Read Foundation. (2008). Facts and statistics. Retrieved on June 10, 2008, from http://www.nifl.gov/nifl/facts/facts.html

Newton County Public Schools. (2008). About us. Retrieved on June 10, 2008, from http://www.newtoncountyschools.org/about/about.asp

No Child Left Behind Act of 2001, 20 USC $\S 6301$ (2001).

Readinga-z.com. (2007). Retrieved on June 1, 2007, from http://www.readinga-z.com. Ann Arbor, MI: Voyager Learning Company.

Reed, R. P., Jones, K. P., Walker, J. M., \& Hoover-Dempsey, K. V. (2000, April). Parents' motivations for involvement in children's education: Testing a theoretical mode. Paper presented at the annual meeting of the American Educational Research Association, New Orleans, LA.

Rodick, D., \& Hengeler, S. (1980). The short-term and long-term amelioration of academic and motivational deficiencies among low-achieving inner-city adolescents. Child Development, 51(4), 1126-1132.

Rodriguez-Brown, F., Fen Li, R. \& Albom, J. (1999). Hispanic parents' awareness and use of literacy-rich environments at home and in the community. Education and Urban Society, 32, 41-58.

Shelton, M. (1990). The impact of others on a child's self esteem. Master's thesis, Midwestern State University, TX.

Shumow, L., \& Lomax, R. (2002). Prediction perceptions of school safety. School Community Journal, 11(2), 93-112.

Simplicio, J. (2005). Homework in the $21^{\text {st }}$ century: The antiquated and ineffectual implementation of a time honored educational strategy. Education 126(1), 138147.

Sui-Chu, H., \& Willms, D. (1996). Effects of parental involvement on eighth grade achievement. Sociology of Education, 69(2), 126-141. 
Tizard, J., Shofield W. N., \& Hewison, J. (1982). Collaboration between teachers and parents assisting children's reading. British Journal of Educational Psychology, $52(1), 1-11$.

Turner, L. \& Johnson, B. (2003). A model of mastery motivation for at-risk preschoolers. Journal of Educational Psychology, 95(3), 495-505.

U.S. Department of Education. (2001). The No Child Left Behind Act of 2001, Public Law 107-110. Washington, DC: Author.

U.S. Department of Health and Human Services. (2008). Administration for Children and Families, Office of Head Start. Retrieved on June 10, 2008, from http://www.acf.hhs.gov/programs/ohs/

Watt, S., \& Martin, P. (1994). Effect of general self-efficacy expectancies on performance attributions. Psychological Reports, 75(2), 951-962.

Woodcock, R., \& Johnson, M. (1990). Woodcock-Johnson psycho-educational batteryrevised. Allen, TX: DLM Teaching Resources.

Woodruff, S., \& Cashmere, J. (1993). Task, domain, and general efficacy: A reexaminetion of the self-efficacy scale. Psychological Reports, 72(2), 423-433.

Yap, K. O., \& Enoki, D. Y. (1994, April). In search of the elusive magic bullet: Parental involvement and student outcomes. Paper presented at the annual meeting of the American Educational Research Association, New Orleans, LA.

Zellman, G. L., \& Waterman, J.M., (1998). Understanding the impact of parent school involvement on children's educational outcomes. The Journal of Educational Research, 91(6), 370-380. 
APPENDIX A 


\title{
MEMORANDUM
}

\author{
To: Tomasine Morrison \\ CC: Dr. Delia Garcia \\ File \\ From: Chris Grayson, CIM, Institutional Review Board Coordinator \\ Date: July 21, 2006 \\ Proposal Title: The Relationship of a Family Home-Learning Program on \\ Parental/Caregiver Efficacy. \\ Approval \# 070706-01
}

Your study was deemed Exempt by the Institutional Review Board at Florida International University on July 7, 2006.

As a requirement of IRB approval you are required to:

1) Submit a completion report (Form B-2) upon completion of your project in order for the file to be closed.

2) Submit a proposal and receive approval for any additions or changes in the procedures involving human subjects.

3) Provide immediate written notification to the IRB of every serious or unusual or unanticipated adverse event as well as problems with the rights or welfare of the human subjects. You must confirm the receipt of serious AE reports with the IRB office.

Special Conditions: N/A

Please note your approval number is indicated above. For further information, you may contact the IRB Coordinator by email at irbiacuc@fiu.edu or visit the OSRA - Human Subjects website at www.osra.fiu.edu. 
APPENDIX B 


\section{Teacher Family Involvement Practices Survey}

Name

Ethnic Origin Caucasian (Non-Hispanic)

Hispanic
School African American (Non-Hispanic)

Asian/Pacific Islander

American Indian/Native Alaskan

Sex __ Male _ Female

How many years have you worked as a full-time teacher?
a. less than 1 year
b. 1-3 years
c. 4-6 years
d. 7-9 years
e. $10-15$ years
f. 16 years or more

What grade levels do you currently teach? (circle all that apply)
a. kindergarten
b. first grade
c. second grade
d. third grade
e. fourth grade
f. fifth grade g. other (please specify)

What is your highest degree earned?
a. BA/BS
b. MA/MS
c. other

Please circle the number of times and/or frequencies of the following practices:

1 Since the beginning of the school

- year, please estimate the number of times you have conducted the following activites:
a) parenting skills workshops
b) family literacy workshops
c) home visits
d) other

$\begin{array}{lllll}0 & 1-2 & 3-4 & 5-6 & 6 \text { or more } \\ 0 & 1-2 & 3-4 & 5-6 & 6 \text { or more } \\ 0 & 1-2 & 3-4 & 5-6 & 6 \text { or more } \\ 0 & 1-2 & 3-4 & 5-6 & 6 \text { or more }\end{array}$

2 During the last

- academic year, please

estimate the

percentage of parents

that you have

contacted through

these approaches:

a) letter or memo 


\begin{tabular}{|c|c|c|c|c|c|c|c|c|c|}
\hline b) telephone & $\mathrm{N}$ & $0 \%$ & $5 \%$ & $10 \%$ & $25 \%$ & $50 \%$ & $75 \%$ & $90 \%$ & ALL \\
\hline c) meeting at school & $\mathrm{N}$ & $0 \%$ & $5 \%$ & $10 \%$ & $25 \%$ & $50 \%$ & $75 \%$ & $90 \%$ & ALL \\
\hline $\begin{array}{l}\text { d) schedule parent- } \\
\text { teacher conferences }\end{array}$ & $\begin{array}{l}\mathrm{N} \\
\mathrm{A}\end{array}$ & $0 \%$ & $5 \%$ & $10 \%$ & $25 \%$ & $50 \%$ & $75 \%$ & $90 \%$ & ALL \\
\hline e) home visits & $\begin{array}{l}\mathrm{N} \\
\mathrm{A}\end{array}$ & $0 \%$ & $5 \%$ & $10 \%$ & $25 \%$ & $50 \%$ & $75 \%$ & $90 \%$ & ALL \\
\hline $\begin{array}{l}\text { f) meeting in the } \\
\text { community }\end{array}$ & $\begin{array}{l}\mathrm{N} \\
\mathrm{A}\end{array}$ & $0 \%$ & $5 \%$ & $10 \%$ & $25 \%$ & $50 \%$ & $75 \%$ & $90 \%$ & ALL \\
\hline g) report card pick up & $\begin{array}{l}\mathrm{N} \\
\mathrm{A}\end{array}$ & $0 \%$ & $5 \%$ & $10 \%$ & $25 \%$ & $50 \%$ & $75 \%$ & $90 \%$ & ALL \\
\hline $\begin{array}{l}\text { h) performances, } \\
\text { sports or other events }\end{array}$ & $\begin{array}{l}\mathrm{N} \\
\mathrm{A}\end{array}$ & $0 \%$ & $5 \%$ & $10 \%$ & $25 \%$ & $50 \%$ & $75 \%$ & $90 \%$ & ALL \\
\hline $\begin{array}{l}\text { i) positive messages } \\
\text { sent home }\end{array}$ & $\begin{array}{l}\mathrm{N} \\
\mathrm{A}\end{array}$ & $0 \%$ & $5 \%$ & $10 \%$ & $25 \%$ & $50 \%$ & $75 \%$ & $90 \%$ & $\mathrm{AL}$ \\
\hline
\end{tabular}

3 Since the school year started estimate

the number of times that you used the following practices to promote volunteers in your classroom/school:

a) personal phone call to parent

b) sent flyers home

c) needs assessment of parent talents and available time

d) other

$0 \quad 1-2 \quad 3-4 \quad 5-6 \quad 6$ or more

$0 \quad 1-2 \quad 3-4 \quad 5-6 \quad 6$ or more

$0 \quad 1-2 \quad 3-4 \quad 5-6 \quad 6$ or more

$0 \quad 1-2 \quad 3-4 \quad 5-6 \quad 6$ or more

4 During a given month estimate the number of times you have used the following activities to assist families in home learning activities:

a) sending home information on homework policies

b) sending home calendars with activities to do at home

c) strategies to promote literacy at home (eg. reading logs, vacation packets)

d) other

$\begin{array}{lllll}0 & 1-2 & 3-4 & 5-6 & 6 \text { or more } \\ 0 & 1-2 & 3-4 & 5-6 & 6 \text { or more } \\ 0 & 1-2 & 3-4 & 5-6 & 6 \text { or more } \\ 0 & 1-2 & 3-4 & 5-6 & 6 \text { or more }\end{array}$

5 As a teacher, what percentage of time

- do you spend promoting the involvement of parents in decisionmaking roles?

a) actively seeking PTA enrollment

b) actively recruiting parents for ESAC membership c) providing incentives for parents to assume decision-making roles

$\begin{array}{ccccccccc}\mathrm{N} & 0 & 5 & 10 & 25 & 50 \% & 75 \% & 90 & \text { ALL } \\ \mathrm{A} & \% & \% & \% & \% & & & \% & \\ \mathrm{~N} & 0 & 5 & 10 & 25 & 50 \% & 75 \% & 90 & \text { ALL } \\ \mathrm{A} & \% & \% & \% & \% & & & \% & \\ \mathrm{~N} & 0 & 5 & 10 & 25 & 50 \% & 75 \% & 90 & \text { ALL } \\ \mathrm{A} & \% & \% & \% & \% & & & \% & \end{array}$


6 Since the school year started

estimate the frequency with which you perform the following activities:

$\begin{array}{llllll}\begin{array}{l}\text { a) coordinate guest speakers } \\ \text { from the community }\end{array} & 0 & 1-2 & 3-4 & 5-6 & 6 \text { or more } \\ \begin{array}{l}\text { b) coordinate field trips for your } \\ \text { students into the community }\end{array} & 0 & 1-2 & 3-4 & 5-6 & 6 \text { or more } \\ \begin{array}{l}\text { c) Recruit business and/or } \\ \begin{array}{l}\text { community organizations as } \\ \text { school partners }\end{array}\end{array} & 0 & 1-2 & 3-4 & 5-6 & 6 \text { or more }\end{array}$

Garcia, D. C., (2004). Exploring connections between the construct of teacher efficacy and family involvement practices: Implications for urban teacher preparation. Urban Education, 39(3), 290-315. 
APPENDIX C 


\section{Family Involvement Teacher Efficacy Scale}

Name

School

Ethnic Origin

Caucasian (Non-Hispanic)

African American (Non-Hispanic)

Hispanic

Asian/Pacific Islander

American Indian/Native Alaskan

Sex __ Male _ Female

How many years have you worked as a full-time teacher?
a. less than 1 year
b. 1-3 years
c. 4-6 years
d. 7-9 years
e. $10-15$ years
f. 16 years or more

What grade levels do you currently teach? (circle all that apply)
a. kindergarten
b. first grade
c. second grade
d. third grade
e. fourth grade
f. fifth grade

g. other (please specify)

What is your highest degree earned?
a. BA/BS
b. MA/MS
c. other

Please circle the most appropriate response.

\begin{tabular}{|l|l|c|c|c|c|c|c|}
\cline { 3 - 7 } \multicolumn{2}{l|}{} & $\begin{array}{c}\text { Strong- } \\
\text { ly } \\
\text { Dis- } \\
\text { agree }\end{array}$ & $\begin{array}{c}\text { Moder- } \\
\text { ately } \\
\text { Dis- } \\
\text { agree }\end{array}$ & $\begin{array}{c}\text { Dis- } \\
\text { agree } \\
\text { slightly } \\
\text { more } \\
\text { than } \\
\text { agree }\end{array}$ & $\begin{array}{c}\text { Agree } \\
\text { slightly } \\
\text { more } \\
\text { than } \\
\text { disagree }\end{array}$ & $\begin{array}{c}\text { Moder- } \\
\text { ately } \\
\text { agree }\end{array}$ & $\begin{array}{c}\text { Strong- } \\
\text { ly } \\
\text { agree }\end{array}$ \\
\hline 2. & $\begin{array}{l}\text { Parents' attitudes towards school } \\
\text { are mostly determined by their } \\
\text { background and demographic } \\
\text { characteristics. }\end{array}$ & 1 & 2 & 3 & 4 & 5 & 6 \\
\hline 3. & $\begin{array}{l}\text { When parents show increased } \\
\text { interest in children's work at } \\
\text { schools it is usually because I've } \\
\text { placed extra effort in sharing with } \\
\text { them samples of their work. }\end{array}$ & 1 & 2 & 3 & 4 & 5 & 6 \\
\hline $\begin{array}{l}\text { Teachers should take time to meet } \\
\text { with parents at least once a year as } \\
\text { a way of effectively getting } \\
\text { involved. }\end{array}$ & 1 & 2 & 3 & 4 & 5 & 6 \\
\hline 4. & $\begin{array}{l}\text { It is the teachers' role to } \\
\text { implement strategies to get } \\
\text { parents to volunteer in school- } \\
\text { related activities. }\end{array}$ & 1 & 2 & 3 & 4 & 5 & 6 \\
\hline
\end{tabular}




\begin{tabular}{|c|c|c|c|c|c|c|c|}
\hline 5. & $\begin{array}{l}\text { Fostering opportunities for parents } \\
\text { and students to participate in } \\
\text { community } \\
\text { programs is not within a teacher's } \\
\text { role. }\end{array}$ & 1 & 2 & 3 & 4 & 5 & 6 \\
\hline 6. & $\begin{array}{l}\text { I don't have the necessary skills to } \\
\text { offer training that may enable } \\
\text { parents to serve as representatives } \\
\text { in decision making bodies. }\end{array}$ & 1 & 2 & 3 & 4 & 5 & 6 \\
\hline 7. & $\begin{array}{l}\text { Teachers should take the time to } \\
\text { seek information related to } \\
\text { students' family background, } \\
\text { culture and parental views and } \\
\text { expectations for their children. }\end{array}$ & 1 & 2 & 3 & 4 & 5 & 6 \\
\hline
\end{tabular}

\begin{tabular}{|c|c|c|c|c|c|c|c|}
\hline & & $\begin{array}{c}\text { Strong- } \\
\text { ly } \\
\text { Dis- } \\
\text { agree }\end{array}$ & $\begin{array}{l}\text { Moder- } \\
\text { ately } \\
\text { Dis- } \\
\text { agree }\end{array}$ & $\begin{array}{c}\text { Dis- } \\
\text { agree } \\
\text { slightly } \\
\text { more } \\
\text { than } \\
\text { agree } \\
\end{array}$ & $\begin{array}{l}\text { Agree } \\
\text { slightly } \\
\text { more } \\
\text { than } \\
\text { disagree }\end{array}$ & $\begin{array}{l}\text { Moder- } \\
\text { ately } \\
\text { agree }\end{array}$ & $\begin{array}{l}\text { Strong- } \\
\text { ly } \\
\text { agree }\end{array}$ \\
\hline 8. & $\begin{array}{l}\text { I can effectively design and utilize } \\
\text { a survey for families to share } \\
\text { information and concerns with me } \\
\text { about their children's goals and } \\
\text { strengths. }\end{array}$ & 1 & 2 & 3 & 4 & 5 & 6 \\
\hline 9. & $\begin{array}{l}\text { As a teacher, I feel that when my } \\
\text { students' basic needs are met at } \\
\text { home, they are more apt to } \\
\text { achieve in my class. }\end{array}$ & 1 & 2 & 3 & 4 & 5 & 6 \\
\hline 10. & $\begin{array}{l}\text { Teachers possess the skills to } \\
\text { design learning activities for } \\
\text { students to complete with parental } \\
\text { assistance. }\end{array}$ & 1 & 2 & 3 & 4 & 5 & 6 \\
\hline 11. & $\begin{array}{l}\text { I can provide parents with the } \\
\text { necessary skills to assume } \\
\text { advocacy roles in their children's } \\
\text { education. }\end{array}$ & 1 & 2 & 3 & 4 & 5 & 6 \\
\hline 12. & $\begin{array}{l}\text { I am capable of working with } \\
\text { language minority parents and } \\
\text { teach them strategies to help their } \\
\text { children at home. }\end{array}$ & 1 & 2 & 3 & 4 & 5 & 6 \\
\hline 13. & $\begin{array}{l}\text { Teachers have the ability of } \\
\text { holding informational meetings } \\
\text { concerning school/classroom } \\
\text { policies, programs and } \\
\text { assessments, as needed. }\end{array}$ & 1 & 2 & 3 & 4 & 5 & 6 \\
\hline 14. & $\begin{array}{l}\text { Teachers possess the knowledge } \\
\text { to provide parents with training in } \\
\text { basic parenting skills. }\end{array}$ & 1 & 2 & 3 & 4 & 5 & 6 \\
\hline 15. & $\begin{array}{l}\text { I feel confident sending folders } \\
\text { with students' work home } \\
\text { periodically for parents' } \\
\text { comments and review. }\end{array}$ & 1 & 2 & 3 & 4 & 5 & 6 \\
\hline
\end{tabular}




\begin{tabular}{|l|l|l|l|l|l|l|l|}
\hline 16. & $\begin{array}{l}\text { Teachers are not very powerful } \\
\text { influences in promoting the } \\
\text { involvement of parents. }\end{array}$ & 1 & 2 & 3 & 4 & 5 & 6 \\
\hline 17. & $\begin{array}{l}\text { I am able to maximize the use of } \\
\text { volunteers by identifying parents } \\
\text { interest and talents. }\end{array}$ & 1 & 2 & 3 & 4 & 5 & 6 \\
\hline 18. & $\begin{array}{l}\text { The awareness and understanding } \\
\text { that parents have about school } \\
\text { courses, programs and activities is } \\
\text { related to their sociocultural } \\
\text { background. }\end{array}$ & 1 & 2 & 3 & 4 & 5 & 6 \\
\hline 19. & $\begin{array}{l}\text { When I see change in homework } \\
\text { completion it is usually because } \\
\text { I've taken an extra step in getting } \\
\text { parents involved in the process. }\end{array}$ & 1 & 2 & 3 & 4 & 5 & 6 \\
\hline 20. & $\begin{array}{l}\text { Teachers should promote the } \\
\text { involvement of parents as } \\
\text { members of school committees } \\
\text { related to safety issues, curriculum } \\
\text { and personnel selection. }\end{array}$ & 1 & 2 & 3 & 4 & 5 & 6 \\
\hline 21. & $\begin{array}{l}\text { I don't know how to effectively } \\
\text { implement strategies to keep } \\
\text { parents informed about school } \\
\text { events and upcoming student } \\
\text { activities. }\end{array}$ & 1 & 2 & 3 & 4 & 5 & 6 \\
\hline 22. & $\begin{array}{l}\text { I am effective at providing enough } \\
\text { opportunities for working parents } \\
\text { to participate in school/classroom } \\
\text { related activities. }\end{array}$ & 1 & 2 & 3 & 4 & 5 & 6 \\
\hline
\end{tabular}

\begin{tabular}{|l|l|c|c|c|c|c|c|}
\cline { 3 - 7 } \multicolumn{2}{l|}{} & $\begin{array}{c}\text { Strong- } \\
\text { ly } \\
\text { Dis- } \\
\text { agree }\end{array}$ & $\begin{array}{c}\text { Moder- } \\
\text { ately } \\
\text { Dis- } \\
\text { agree }\end{array}$ & $\begin{array}{c}\text { Dis- } \\
\text { agree } \\
\text { slightly } \\
\text { more } \\
\text { than } \\
\text { agree }\end{array}$ & $\begin{array}{c}\text { Agree } \\
\text { slightly } \\
\text { more } \\
\text { than } \\
\text { disagree }\end{array}$ & $\begin{array}{c}\text { Moder- } \\
\text { ately } \\
\text { agree }\end{array}$ & $\begin{array}{c}\text { Strong- } \\
\text { ly } \\
\text { agree }\end{array}$ \\
\hline 23. & $\begin{array}{l}\text { Teachers play a crucial role in } \\
\text { providing parents with the needed } \\
\text { skills to support their children in } \\
\text { school. }\end{array}$ & 1 & 2 & 3 & 4 & 5 & 6 \\
\hline 25. & $\begin{array}{l}\text { Teachers can effectively get } \\
\text { parents to understand the } \\
\text { importance of joining } \\
\text { organizations and actively } \\
\text { participating in groups such as the } \\
\text { PTA/PTSA. }\end{array}$ & 1 & 2 & 3 & 4 & 5 & 6 \\
\hline 26. & $\begin{array}{l}\text { I feel frustrated in my attempts at } \\
\text { involving parents. }\end{array}$ & 1 & 2 & 3 & 4 & 5 & 6 \\
\hline $\begin{array}{l}\text { I can design and implement a } \\
\text { parent workshop that will provide } \\
\text { parents with strategies to assist } \\
\text { their children with specific skills. }\end{array}$ & 1 & 2 & 3 & 4 & 5 & 6 \\
\hline
\end{tabular}




\begin{tabular}{|c|c|c|c|c|c|c|c|}
\hline 27. & $\begin{array}{l}\text { I do not have enough training to } \\
\text { provide parents with suggestions } \\
\text { on parenting and child rearing } \\
\text { practices for the age and grade } \\
\text { levels I teach/work with. }\end{array}$ & 1 & 2 & 3 & 4 & 5 & 6 \\
\hline 28. & $\begin{array}{l}\text { I am capable of setting up parent } \\
\text { conferences at least once a year to } \\
\text { discuss students' progress. }\end{array}$ & 1 & 2 & 3 & 4 & 5 & 6 \\
\hline 29. & $\begin{array}{l}\text { Teachers cannot change the } \\
\text { realities of the home environment } \\
\text { facing many students in today's } \\
\text { classrooms. }\end{array}$ & 1 & 2 & 3 & 4 & 5 & 6 \\
\hline 30. & $\begin{array}{l}\text { Teachers have received the } \\
\text { preparation training to provide } \\
\text { parents with skills to monitor and } \\
\text { assist with schoolwork at home. }\end{array}$ & 1 & 2 & 3 & 4 & 5 & 6 \\
\hline 31. & $\begin{array}{l}\text { I am unable to implement } \\
\text { effective practices and activities } \\
\text { focused on increasing parental } \\
\text { involvement due to my numerous } \\
\text { responsibilities. }\end{array}$ & 1 & 2 & 3 & 4 & 5 & 6 \\
\hline 32. & $\begin{array}{l}\text { Teachers should not be burdened } \\
\text { with the responsibility of finding } \\
\text { ways to get parents involved in } \\
\text { family support programs related to } \\
\text { nutrition, health, and parenting } \\
\text { skills. }\end{array}$ & 1 & 2 & 3 & 4 & 5 & 6 \\
\hline 33. & $\begin{array}{l}\text { When communicating with } \\
\text { parents, barriers such as cultural } \\
\text { or language differences are } \\
\text { difficult to overcome by teachers. }\end{array}$ & 1 & 2 & 3 & 4 & 5 & 6 \\
\hline 34. & $\begin{array}{l}\text { When my students are showing } \\
\text { progress it is usually because I } \\
\text { have been able to effectively } \\
\text { engage their parents in providing } \\
\text { additional support at home. }\end{array}$ & 1 & 2 & 3 & 4 & 5 & 6 \\
\hline 35. & $\begin{array}{l}\text { Even when I really try, I can't get } \\
\text { through most parents of students } \\
\text { at my school. }\end{array}$ & 1 & 2 & 3 & 4 & 5 & 6 \\
\hline
\end{tabular}

Garcia, D. C., (2004). Exploring connections between the construct of teacher efficacy and family involvement practices: Implications for urban teacher preparation. Urban Education, 39(3), 290-315. 
APPENDIX D 


\section{H.E.L.P.}

\section{Home Education Literacy Program}

A program designed to assist you and your child in reading at home.

What you should know about H.E.L.P.

- H.E.L.P. provides weekly home-learning activities in reading for you to share with your child.

- The program will run for 12 weeks.

- Each activity will take approximately 15 minutes.

- The activities can be completed in 5 separate sessions or can be combined to fit your family's schedule.

- H.E.L.P. packets will replace ordinary homework assignments.

If you have any questions, please contact Mrs. Morrison at $678-878-* * * *$.

Thank you so much! 


\section{Home-learning Education Literacy Program}

Date

PERSONAL INFORMATION

Name

Child's Name

Phone Number

PARENTAL EDUCATION

Mother's education:

Elementary School

Some High School

High school graduate or GED

Some College

College Degree

Father's education:

Elementary School

Some High School

High school graduate or GED

Some College

College Degree

Language most often spoken in the home

FAMILY INCOME LEVEL (per year)

0-20,000

20,000-40,000 


\section{H.E.L.P. Parent Questionnaire}

Please answer each question. Return this questionnaire to your child's teacher.

1. I provide a space and materials to complete homework assignments. always sometimes seldom never 1 2 3

2. I complete homework during a regular time set for homework. never 1-2 times a week

3-4 times a week

5 times a week 1 2 3

3. I communicate with the teacher concerning homework. (phone, agenda, notes, email) never 1-2 times a week 3-4 times a week 5-6 times a week 7 or more

$\begin{array}{llll}1 & 2 & 3 & 4\end{array}$

45

4. I supervise the completion of homework assignments. never 1-2 times a week 3-4 times a week 5 times a week 1 2 3 4

5. I correct homework. never

1-2 times a week

3-4 times a week

1 2 3

5 times a week

6. I provide rewards for homework completion. always sometimes seldom never 123

7. I spend minutes each night on reading homework.

$\begin{array}{ccccc}\text { never } & 1-10 \text { minutes } & 11-20 \text { minutes } & 21-30 \text { minutes } & 31 \text { or more } \\ 1 & 2 & 3 & 4 & 5\end{array}$

8. I read with my child as part of weekly homework.

never 1-2 times a week 3-4 times a week 5 times a week

$\begin{array}{llll}1 & 2 & 3 & 4\end{array}$

9. I write with my child as part of weekly homework.

never 1-2 times a week 3-4 times a week 5 times a week 123

10. My child completes homework assignments.

$\begin{array}{cccc}\text { never } & 1-2 \text { times a week } & 3-4 \text { times a week } & 5 \text { times a week } \\ 1 & 2 & 3 & 4\end{array}$




\section{Parent Perceptions of Parent Efficacy Scale*}

11. I know how to help my child do well in school.

$\begin{array}{ccccc}\text { strongly agree } & \text { agree } & \text { neither agree nor disagree } & \text { disagree } & \text { strongly disagree } \\ 5 & 4 & 3 & 2 & 1\end{array}$

12. My child is so complex I never know if I'm getting through to him/her. strongly agree agree neither agree nor disagree disagree strongly disagree $\begin{array}{lllll}5 & 4 & 3 & 2 & 1\end{array}$

13. I don't know how to help my child make good grades in school. $\begin{array}{ccccc}\text { strongly agree } & \text { agree } & \text { neither agree nor disagree } & \text { disagree } & \text { strongly disagree } \\ 5 & 4 & 3 & 2 & 1\end{array}$

14. A student's motivation to do well in school depends on the parents. strongly agree agree neither agree nor disagree disagree strongly disagree $\begin{array}{lllll}5 & 4 & 3 & 2 & 1\end{array}$

15. I feel successful about my efforts to help my child learn. strongly agree agree neither agree nor disagree disagree strongly disagree 5 $4 \quad 3 \quad 2 \quad 1$

16. Other children have more influence on my child's grades than I do. $\begin{array}{ccccc}\text { strongly agree } & \text { agree } & \text { neither agree nor disagree } & \text { disagree } & \text { strongly disagree } \\ 5 & 4 & 3 & 2 & 1\end{array}$

17. Most of a student's success in school depends on the classroom teacher, so I have only limited influence.

strongly agree agree neither agree nor disagree disagree strongly disagree

$\begin{array}{lllll}5 & 4 & 3 & 2 & 1\end{array}$

18. I don't know how to help my child learn.

$\begin{array}{ccccc}\text { strongly agree } & \text { agree } & \text { neither agree nor disagree } & \text { disagree } & \text { strongly disagree } \\ 5 & 4 & 3 & 2 & 1\end{array}$

19. If I try hard, I can get through to my child even when he or she has difficulty understanding something.

$\begin{array}{ccccc}\text { strongly agree } & \text { agree } & \text { neither agree nor disagree } & \text { disagree } & \text { strongly disagree } \\ 5 & 4 & 3 & 2 & 1\end{array}$

3

2

1 
20. I make a significant difference in my child's school performance. $\begin{array}{ccccc}\text { strongly agree } & \text { agree } & \text { neither agree nor disagree } & \text { disagree } & \text { strongly disagree } \\ 5 & 4 & 3 & 2 & 1\end{array}$

21. Other children have more influence on my child's motivation to do well in school than I do.

$\begin{array}{ccccc}\text { strongly agree } & \text { agree } & \text { neither agree nor disagree } & \text { disagree } & \text { strongly disagree } \\ 5 & 4 & 3 & 2 & 1\end{array}$

22. My efforts to help my child learn are successful.

$\begin{array}{ccccc}\text { strongly agree } & \text { agree } & \text { neither agree nor disagree } & \text { disagree } & \text { strongly disagree } \\ 5 & 4 & 3 & 2 & 1\end{array}$

Hoover-Dempsey, K., Bassler, O., \& Brissie, J. (1992). Explorations in parent-school relations. Journal of Educational Research, 85(5), 287-294. 
APPENDIX E 


\section{Days of Reading Homework}

Dear Parents,

In What's for Dinner, Giraffe is hungry, but he is tired of eating leaves. How will Giraffe solve his problem? He decides to try to eat foods other animals eat. Humorous, supportive pictures and repetitive phrases allow early readers to be successful.

\section{Weekly Book: What's for Dinner? By: Chitra Soundar}

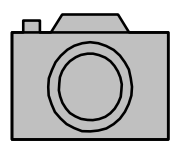

\section{Day 1: Preview/Picture Walk}

- Ask your child the following questions before reading:

Ask your child to explain the meaning of the word dinner. Invite them to share what they like to eat for dinner. Ask him/her what they think animals eat for dinner.

Discuss the similarities and differences between the kinds of food that different animals eat. Have him/her explain why some animals might eat certain foods.

\footnotetext{
- Show your child the front and back covers of the book and read the title with them. Ask why they might read about in a book called What's for Dinner?

- Show your child the title page. Discuss the information on the page. Share the Title and Author's name.

- Ask your child to name the animals that they see in the pictures.
} 


\section{Day 2: Vocabulary Activity}

- Show the word to your child.

- Read the definition.

- Read the sentence.

- Read the story- stop when you come to one of the vocabulary words.

- Ask your child to repeat the definition.

\section{Vocabulary:}

bird- an animal that flies and has feathers and eats seeds

giraffe- a large animal with a long neck that lives in Africa.

otter- a playful animal that likes the water and eats fish

leaves-a part of a plant that some animals like to eat

frog- an animal that is green and lives in the water and eats bugs

delicious- tasting very, very good 
Day 3: Reading Comprehension

- $\quad$ Explain that most stories have a problem that the main character needs to fix. The solution is how the problem is fixed.

- Model how to identify the problem and solution using a familiar story. Think-aloud: In the story of Little Red Riding Hood, Little Red could not escape the wolf at her grandmother's house. This was a problem for her because the wolf was able to swallow her up. However, when a woodsman saw the wolf in the grandmother's house, he knew something was wrong. He rescued Little Red Riding Hood and her grandmother from the wolf.

- Have your student think of familiar stories to share. Discuss the problems and solutions in each story.

Comprehension Questions

What was Giraffe's main problem in

the story?

What made Giraffe's neck hurt?

What did Giraffe try to eat after the honey?

What does delicious mean?

What happened when Giraffe tried to eat ants? 


\section{Day 4: Reading with Tracking}

- Read the story with your child.

- During the reading have your child point to each word as you read it.

\section{Extending activity:}

- Discuss foods that animals eat and why they might eat the foods they do. For example, Giraffes eat leaves because they have a long neck and tongue to reach them in the trees.

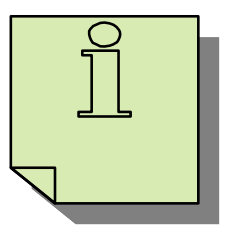

Day 5: Journal Activity

- On the lines below let your child write freely about the prompt below.

- You child may also illustrate their writing. 


\section{PROMPT}

Have the student dictate or write why Giraffe decided leaves were so good to eat at the end of the story. Draw a picture to illustrate. 


\section{VITA}

TOMASINE A. MORRISON

Jan. 1984

1987-2002

June 1989

1990

1996

1998-2002

2002-2003

2003-2005

2005-Present
Bachelor of Science in Education Westfield State College

Westfield, Massachusetts

Sixth, Second, First, Kindergarten, ESOL Teacher

Miami-Dade County Public Schools

Miami, Florida

Graduate Certificate in Urban Education Florida International University

Miami, Florida

Master of Science in Urban Education

Florida International University

Miami, Florida

Educational Specialist Degree

Florida International University

Miami, Florida

Title I Reading Leader

Miami-Dade County Public Schools

Miami, Florida

Kindergarten Teacher

E.L. Connally Elementary School

Atlanta, Georgia

First Grade Teacher

Stockbridge Elementary School

Stockbridge, Georgia

Special Education Teacher

Porterdale Elementary School

Covington, Georgia 